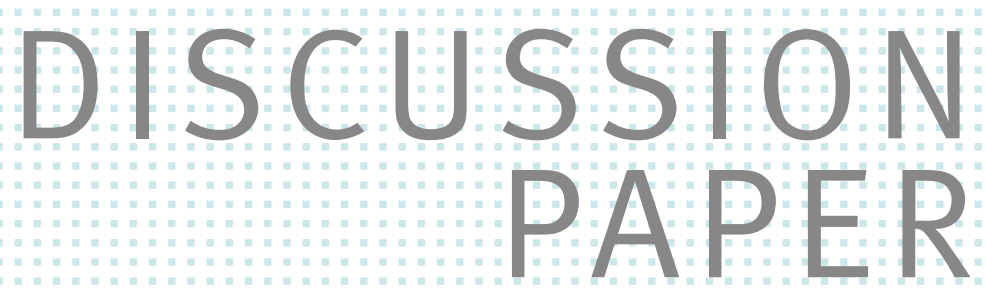

/ / OLIVER KALSBACH AND SEBASTIAN RAUSCH

Pricing Carbon in a Multi-Sector Economy With Social Discounting 


\title{
Pricing Carbon in a Multi-Sector Economy with Social Discounting
}

\author{
By Oliver Kalsbach and Sebastian Rausch*
}

August 2021

\begin{abstract}
Economists tend to view a uniform emissions price as the most cost-effective approach to reducing greenhouse gas emissions. This paper offers a different view, focusing on economies where society values the well-being of future generations more than private actors. Employing analytical and numerical general equilibrium models, we show that a uniform carbon price is efficient only under restrictive assumptions about technology homogeneity and intertemporal decision-making. Non-uniform pricing spurs capital accumulation and benefits future generations. Depending on sectoral heterogeneity in the substitutability between capital and energy inputs, we find that optimal carbon prices differ widely across sectors and yield substantial welfare gains relative to uniform pricing.
\end{abstract}

Keywords: Sectoral Carbon Pricing, Differentiated Carbon Taxes, Climate Policy, Social Discounting

JEL: Q54, Q58, Q43, H23, C61

Climate change is a long-term problem - the costs of avoiding greenhouse gas emissions must be justified by the benefits of avoided impacts well into the future. At the same time, efficient climate change mitigation requires avoiding emissions where it is cheapest. In most economies, however, the marginal costs of reducing emissions vary widely across sectors and technologies. Economists have long argued that a uniform price on carbon dioxiode $\left(\mathrm{CO}_{2}\right)$ emissions minimizes the welfare costs of achieving an economy-wide emissions target as it incentivizes abatement up to the point where marginal abatement costs are equalized (Cropper and Oates, 1992; Goulder and Parry, 2008; Metcalf, 2009).

This has strong implications for the contribution that each sector should make in a country's decarbonization effort. For example, if the marginal cost of reducing emissions in a heavily coal-based electricity sector is lower than the cost of reducing emissions in private transport or buildings, where the opportunities for substituting fossil energy for capital are more expensive and limited, the electricity sector should reduce emissions more than these sectors. This, of course, is precisely the idea behind the standard climate policy recommendation to "put a price on carbon," which manifests itself in numerous proposals for efficient climate policy—for

* Oliver Kalsbach (email: okalsbach@ethz.ch), Department of Management, Technology and Economics, ETH Zurich, Switzerland. Sebastian Rausch (sebastian.rausch@zew.de), ZEW Leibniz Centre for European Economic Research, Mannheim, Germany, Department of Economics, Heidelberg University, Germany, Centre for Energy Policy and Economics at ETH Zurich, Switzerland, and Joint Program on the Science and Policy of Global Change at Massachusetts Institute of Technology, Cambridge, USA. 
example, the idea of a global, comprehensive carbon price as once envisioned under the Kyoto Protocol, expanding the scope of major emissions trading schemes in Europe, the United States, and China, or linking regional carbon pricing regimes (Nordhaus, 2015).

As economies around the world pursue increasingly ambitious decarbonization goals for the whole economy, the question of how to price $\mathrm{CO}_{2}$ emissions in different sectors is of great importance. It is all the more surprising that the economic discipline has so far overlooked the idea that optimal carbon pricing in a multisector economy is intricately linked to how private and public decision-makers value the costs and benefits of climate policy over time. Intuitively, if society or a benevolent social planner places a higher value on the well-being of future generations than private agents do, agents discount the future too much and the government should promote future oriented policies, i.e. policies which increase the capital stock. The transformation to a green economy requires a massive substitution of capital for fossil energy, but the substitutability of capital and fossil energy varies widely across sectors, depending on technology. Thus, while it appears desirable from a partial equilibrium perspective to price carbon uniformly, efficient multi-sector carbon pricing that enables "large" transformations requires considering the heterogeneous general equilibrium effects on capital accumulation and their social valuation.

In this paper, we examine optimal carbon pricing in a multi-sector economy when private agents and the social planner discount utility differently. We do not propose a new model but base our analysis on a standard neoclassical growth model where capital substitutes for $\mathrm{CO}_{2}$ emissions that are a by-product of fossil fuel combustion in sectoral production. We focus on cost-effectiveness and ask how carbon should be priced to meet an exogenously specified economy-wide emissions budget at the lowest cost. ${ }^{1}$ We question the generality of the established wisdom that efficient carbon pricing entails a single, uniform price across different sectors. We show that this view rests on restrictive and unrealistic assumptions once social discounting is taken into account: either different economic sectors are "identical" in terms of substitutability of capital and energy inputs, or the capital stock is exogenous. We show that technology heterogeneity causes optimal $\mathrm{CO}_{2}$ prices to differ across sectors, and quantitatively explore the welfare gains relative to uniform carbon pricing for the European economy. We explore the implications of optimally differentiated $\mathrm{CO}_{2}$ prices for the design of emissions trading systems as a major market-based instrument for climate policy.

Before summarizing our results in greater detail, it is useful to set the stage for social discounting. Evaluation over time is a recurring and highly controversial topic in economics, especially when the costs and benefits are evaluated over very long time scales, as is the case with climate change. For many philosophers (Sidgwick, 1874; Broome, 1994) and economists (Ramsey, 1928; Pigou, 1932; Solow, 1974) intergenerational discounting is ethically indefensible: basic fairness, i.e. im-

\footnotetext{
${ }^{1}$ We abstract from the benefits of averted climate change and endogenous environmental quality which are subject of study in integrated assessment models (see, for example, Nordhaus, 2000; Tol, 2009).
} 
partiality, non-discrimination, and equal treatment, rule out discounting. ${ }^{2}$ Zero or near-zero discount rates, however, do not align with households' inter-temporal preferences as revealed through their savings behavior (Nordhaus, 2007; Dasgupta, 2008). Social discounting reconciles both perspectives, allowing the planner to place a higher welfare weight on future generations above the current generation's private altruism towards the future (Bernheim, 1989; Fahri and Werning, 2007; Kaplow, Moyer and Wiesbach, 2010; Goulder and Williams, 2012). Accepting the view that society places more importance on future generations than private actors is, of course, controversial and debatable. ${ }^{3}$ Our goal is not to enter this debate, but to analyze the extent to which the established wisdom that uniform carbon pricing is efficient can be upheld when social discounting is indeed accepted as a reasonable premise.

We start from the result previously shown by Barrage (2018) that under social discounting, a planner in a first-best setting uses a capital income subsidy to equalize social and private marginal returns to savings. We show that if capital income subsidies can be optimally chosen, sectoral $\mathrm{CO}_{2}$ prices are uniform. In reality, however, capital income as a whole is taxed and not subsidized. Moreover, climate policy is usually pursued separately from fiscal policy; in particular, it is not directly linked to policy decisions on capital taxation. We thus argue that the relevant perspective for carbon pricing policy is to assume that capital income as a whole cannot be subsidized.

Given the two premises of social discounting and no capital income subsidies, we show that uniform carbon pricing is only efficient, if social and private "market" discount rates coincide. When discount rates differ, a uniform carbon price is only efficient if climate policy either ignores the effects of a carbon price on investment and capital accumulation or assumes that sectoral production technologies are identical. Both are clearly unreasonable.

Technological heterogeneity across sectors is key to our main result: efficient multi-sector carbon pricing differentiates $\mathrm{CO}_{2}$ prices across sectors. The economic intuition we provide for this result is based on the heterogeneous sectoral responses to a carbon price in adjusting capital and fossil energy $\left(\mathrm{CO}_{2}\right.$ emissions) inputs. Sectors in which $\mathrm{CO}_{2}$ emissions are not easily substitutable with "clean" capital should receive a lower carbon price than sectors where these two inputs are better substitutes. When capital in a given sector is a "poor" substitute for emissions, pricing carbon destroys more capital as compared to reducing the same amount of $\mathrm{CO}_{2}$ emissions in a sector with a higher substitutability. If the social valuation of

\footnotetext{
${ }^{2}$ Robert Solows argumentation against intergenerational discounting of utility is in line with Pigou and Ramsey, stating that "[in] social decision making, however, there is no excuse for treating generations unequally, and the time-horizon is, or should be, very long" (Solow, 1974, p. 9).

${ }^{3}$ When individuals discount both the past and the future, Caplin and Leahy (2004) show that policy makers should be more patient than private citizens, whose choices define the most short-sighted Pareto optimum. From a non-academic perspective, there is also evidence of such a view. Recently, the Federal Constitutional Court (2021) has ruled that the "German Climate Law" in its current form violates the civil liberties of future generations. In particular, it is not acceptable to postpone necessary $\mathrm{CO}_{2} \mathrm{emissions}$ reductions largely into the future in order to spare the present. This can be interpreted as support for the view that society should not only explicitly consider the well-being of future generations in today's policy decisions, but give it more weight.
} 
capital and future wealth were based on the "market" discount rate, the sectoral allocations of $\mathrm{CO}_{2}$ emissions and capital stemming from the equilibrium decisions of firms and households would also be efficient from a social perspective. With social discounting, however, economic agents discount the future too much and differentiating sectoral $\mathrm{CO}_{2}$ prices avoid households failing to invest sufficiently in the economy's capital stocks: it directs capital to where it is socially most valuable, increasing capital accumulation and benefiting future generations.

Multi-sector carbon pricing also constitutes a first-order deviation from uniform carbon pricing from a quantitative perspective. To explore the relevance of our theoretical results in an empirical context, we use a steady-state model which is calibrated to the European economy and resolves major economic sectors. Incorporating empirical estimates on sector-specific capital-energy substitutabilities, we find that the $\mathrm{CO}_{2}$ price differentiation across sectors is significant. For example, for a $40 \%$ economy-wide emissions reduction in the European economy, optimal sectoral prices range from $€ 42.3$ to $€ 116.9$ per ton of $\mathrm{CO}_{2}$, with an emissions-weighted mean $\mathrm{CO}_{2}$ price of $€ 74.4 /$ ton. By comparison, achieving the same emissions target would require a price of $€ 91.3 /$ ton. The variation in optimal $\mathrm{CO}_{2}$ prices is not much affected by considering lower or higher economy-wide emissions reduction targets: the coefficient of variation of optimal sectoral $\mathrm{CO}_{2}$ prices is roughly constant at $40 \%$ for targets of up to $80 \%$.

Compared to uniform carbon pricing, the failure to differentiate $\mathrm{CO}_{2}$ prices by sector forgoes potentially large welfare gains. The magnitude of welfare gains largely depends on technology heterogeneity. For intermediate cases, based on or close to the empirical estimates of sector-specific capital-energy substitutability, we calculate that the welfare cost of climate policy to achieve a $20 \%$ emissions reduction reduces by $14-22 \%$ per period. If the economy is composed of sectors in which some sectors have strong capital-energy substitutability while others have strong capital-energy complementarity, the reduction in welfare costs can be as high as 50\% per period. In contrast, if capital and energy are highly substitutable in all sectors, the welfare gains from differentiating $\mathrm{CO}_{2}$ prices are negligible. In general, welfare gains decrease as emissions reductions increase.

Our findings have important implications for the design of emissions trading systems (ETSs): a single, comprehensive ETS is not optimal when private and social discount rates differ and sectoral production technologies differ. This runs counter to the established policy recommendation to broaden the scope of an ETS or integrate the carbon markets of separate ETSs (Böhringer, Hoffmann and de LaraPeñate, 2006; Abrell and Rausch, 2017). We show that when $\mathrm{CO}_{2}$ emissions are regulated by two ETSs within a jurisdiction, price differences between the systems need not be costly. In fact, two separate ETSs may be superior to a single, comprehensive ETS if sectors are assigned to each ETS in such a way that sectors with relatively low and high capital-energy substitutability are clustered separately. These considerations are relevant to the practical design of ETSs, especially since decarbonization efforts in many countries relies on one or more markets for tradable emission permits as the cornerstone of climate policy.

The results of our analysis are also relevant for model-based evaluations of cli- 
mate policy. First, model-based evaluations of climate policy which macroeconomic models which adopt a single-output framework (for example, DICE-type models by Nordhaus, 2007; Barrage, 2018), assume that social and private discount rates are equal, and ignore technology heterogeneity amount to assuming that a uniform carbon price is optimal. To the extent that these assumptions are not warranted, they overlook better approaches to carbon pricing and thus overstate the costs of climate policy. Second, models which adopt a richer multi-sector perspective, on the other hand, are often static (Böhringer, Carbone and Rutherford, 2016; Landis, Rausch and Kosch, 2018) or assume myopic economic agents ruling out that expectations affect the future capital stock - for example, models used for climate policy assessments by the European Commission (Capros et al., 2013) and in the academic community (Paltsev et al., 2005; Fawcett et al., 2014; Thompson et al., 2014). Simplifying the intertemporal decision rules in such ways also effectively assumes that a uniform carbon price is optimal. Third, the partial equilibrium result of a uniform cost-effective pricing of emissions can only be transferred to a general equilibrium under restrictive assumptions. Partial equilibrium evaluations should thus be used with caution.

More generally, our analysis contributes to the large body of literature on discounting in the context of climate change mitigation (Stern, 2006; Nordhaus, 2007; Weitzman, 2007). Previous work has pointed out that a clearer distinction should be made between the concepts of social and private "market" discount rates when evaluating climate policies (Kaplow, Moyer and Wiesbach, 2010; Goulder and Williams, 2012; van der Ploeg and Rezai, 2019). von Below (2012) is the first to operationalize both concepts in one framework for climate policy analysis. Most closely related to our analysis, Barrage (2018) shows that if the government cannot subsidize capital income, the constrained-optimal carbon tax may be up to $50 \%$ below the present value of marginal damages (the social cost of carbon) due to the general equilibrium effects of climate policy on household savings. We contribute by providing the first analysis which examines optimal multi-sector carbon pricing when social and private discount rates differ.

Non-uniform pollution prices have been found to be optimal in economies that feature either imperfectly competitive markets (Sandmo, 1975; Markusen, 1975; Krutilla, 1991; Rauscher, 1994), settings where social equity concerns over heterogeneous households are present (Landis, Rausch and Kosch, 2018; Abrell, Rausch and Schwarz, 2018), or when border adjustment tariffs on carbon leakage are not possible (Hoel, 1996). This paper adds an important new motive for non-uniform pollution prices.

Section I describes the economic environment and sets up the social planning problem. Section II presents our qualitative results. Section III describes the calibration of the numerical model. In Section IV we explain the computational experiments, with results presented in Section V. Section VI provides additional sensitivity analysis. Section VII concludes. Proofs are contained in the Appendix. 


\section{The Economic Environment}

\section{A. Private and Social Discounting}

Following recent literature (see, for example, Barrage, 2018; Belfiori, 2017; Fahri and Werning, 2007), we assume that the social planner places positive weight on future generations' welfare above and beyond the current living population's private altruism. Social discounting thus means that there is a disagreement in utility discount factors between a dynastic household $(\zeta)$ and the social planner $\left(\zeta_{S}\right)$ and that $\zeta>\zeta_{S} \geq 0$. Time is discrete and extends to infinity $t=0, \ldots, \infty$. Dynastic households maximize:

$$
U=\sum_{t=0}^{\infty} \frac{1}{(1+\zeta)^{t}} u\left(C_{t}\right)
$$

where $u\left(C_{t}\right)$ is a standard concave period utility function which allows for general CRRA preferences: $u\left(C_{t}\right)=C_{t}^{1-\sigma} /(1-\sigma)$. $1 / \sigma$ denotes the elasticity of inter temporal substitution, $C_{t}$ is consumption of a final good at time $t$, and $\zeta$ is the private discount rate of households. The social planner maximizes the social welfare function: ${ }^{4}$

$$
\begin{aligned}
& W=\sum_{t=0}^{\infty} \frac{1}{\left(1+\zeta_{S}\right)^{t}} u\left(C_{t}\right) . \\
& \text { B. Decentralized Economy }
\end{aligned}
$$

HOUSEHOLDS.- Household earn income from supplying labor at the market rate $w_{t}$, return $R_{t}$ (net of depreciation) minus capital income tax $\Xi_{t}$ on capital holdings $K_{t}$, profits from sectoral production $\Pi_{t}$, and lump-sum transfers $\Lambda_{t}$ from the government which comprise revenues from taxing carbon emissions and capital income. The households' budget constraint is given by:

$$
C_{t}+\bar{K}_{t+1} \leq w_{t} \bar{L}+\left[1+R_{t}\left(1-\Xi_{t}\right)\right] \bar{K}_{t}+\Pi_{t}+\Lambda_{t},
$$

where $\bar{L}$ denotes the perfectly inelastic aggregated labor supply and $\bar{K}_{t}$ denotes the aggregated capital supply at time $t$.

Households maximize (1) subject to (3), yielding the following savings optimality condition, which relates the costs of forgone consumption today to the discounted value of future capital income:

$$
U_{C t}=\frac{1}{1+\zeta} U_{C t+1}\left(1+R_{t+1}\left(1-\Xi_{t+1}\right)\right),
$$

where $U_{C t}:=\partial u\left(C_{t}\right) / \partial C_{t}$.

\footnotetext{
${ }^{4}$ Bernheim (1989) and Barrage (2018) show that the social welfare function corresponds to a timeconsistent social planner's problem for appropriately chosen welfare weights.
} 
PRODUCTION. - The final good at time $t, \hat{Y}_{t}$, is produced by profit-maximizing firms using contemporaneous output of sector $j, k=1, \ldots, J, Y_{j t}$, with a linearly homogeneous production function:

$$
\hat{Y}_{t}=\prod_{j=1}^{J} Y_{j t}^{\gamma_{j}}
$$

where $\gamma_{j}$, with $\sum_{j} \gamma_{j}=1$, is a share parameter.

Sectoral goods $Y_{j t}$ are produced using labor, capital, and $\mathrm{CO}_{2}$ emissions inputs according to a constant-elasticity-of-substitution (CES) production function:

$$
Y_{j t}=L_{j t}^{\alpha_{j}}\left[\beta_{K j}\left(H_{K j} K_{j t}\right)^{\rho_{j}}+\beta_{E j}\left(H_{E j} E_{j t}\right)^{\rho_{j}}\right]^{\frac{1-\alpha_{j}}{\rho_{j}}}
$$

where $\alpha_{j}$ and $\beta$ s are share parameters, and $\beta_{K j}+\beta_{E j}=1 . H_{K j}$ and $H_{E j}$ denote the input- and sector-specific productivity factors of capital and emissions. $-\infty<\rho_{j}<$ 1 denotes the elasticity parameter and is related to the elasticity of substitution $\sigma_{j}=1 /\left(1-\rho_{j}\right)$. Throughout, we say that inputs in production are substitutes when $\rho_{j}>0$ and complements when $\rho_{j}<0 . \rho_{j}=0$ indicates the Cobb-Douglas case. $L_{j t}, K_{j t}$, and $E_{j t}$ denote the amount of labor, capital, and $\mathrm{CO}_{2}$ emissions used in sector $j$ at time $t$, respectively.

Firms maximize profits taking prices as given on perfectly competitive output and factor markets. The optimal input choices $K_{j t}, L_{j t}, E_{j t}$, and $Y_{j t}$ are therefore determined by:

$$
r_{j t}=p_{j t} \frac{\partial Y_{j t}}{\partial K_{j t}}, \quad w_{t}=p_{j t} \frac{\partial Y_{j t}}{\partial L_{j t}}, \quad \tau_{j t}=p_{j t} \frac{\partial Y_{j t}}{\partial E_{j t}}, \quad p_{j t}=\hat{p}_{t} \frac{\partial \hat{Y}_{t}}{\partial Y_{j t}},
$$

where $p_{j t}$ and $\hat{p}_{t}$ denote the prices for sectoral output $Y_{j t}$ and final output $\hat{Y}_{t}$, respectively. We choose the price of final output as the numeraire $\left(\hat{p}_{t}=1\right)$.

We focus specifically on multi-sector economies with technology heterogeneity. Sectors are said to be heterogeneous if share parameters $\beta_{K j}$, substitution parameters $\rho_{j} \neq 0$, input factor-specific productivities $\left(H_{K j}, H_{E j}\right)$, or sector-specific depreciation rates $\delta_{j}$ or a combination of these parameters, differ across sectors. Two sectors are identical if these parameters take on the same respective value or if $\rho_{j}=0$ across the two sectors.

Market clearing conditions of labor and capital at time $t$ are:

$$
\sum_{j=1}^{J} L_{j t}=\bar{L}, \quad \forall j: K_{j t}=\bar{K}_{j t},
$$

such that $\bar{L}$ is perfectly mobile across sectors, and $\bar{K}_{j t}$ denotes the capital supplied to sector $j$ at time $t$. Aggregated capital, $\bar{K}_{t}=\sum_{j} \bar{K}_{j t}$, accumulates over time 
according to:

$$
\sum_{j=1}^{J} \bar{K}_{j t+1}=\sum_{j=1}^{J}\left(1-\delta_{j}\right) \bar{K}_{j t}+I_{t},
$$

where $\delta_{j}$ is the sector-specific, periodic depreciation rate and $I_{t}$ denotes investments. Capital is homogeneous and mobile across sectors such that the return net of sectorspecific depreciation is equal across the economy, i.e. households base their savings decision on $R_{t}=r_{j t}-\delta_{j}, \forall j$. We include sector-specific capital rental rates to incorporate an additional aspect of sectoral heterogeneity.

The final good can be used for investment and consumption purposes:

$$
C_{t}+I_{t}=\hat{Y}_{t} .
$$

CARBON EMISSIONS.- $\mathrm{CO}_{2}$ emissions are the by-product created by the combustion of fossil fuels inputs in production. To simplify, we abstract from explicitly including energy (from fossil fuels) and instead directly represent $\mathrm{CO}_{2}$ emissions as an input in production. ${ }^{5}$

At the center of our analysis is the investigation of sectorally differentiated carbon prices. We thus include $J$ separate emission markets at each point in time which determine sectoral emissions prices, $\tau_{j t}$ :

$$
E_{j t}=\bar{E}_{j t} .
$$

$\bar{E}_{j t}$ denotes the sector- $j$ emissions budget, where in addition the sum of sectoral emissions is constrained by an exogenously given economy-wide emissions budget, $\bar{E}_{t}$, according to:

$$
\sum_{j=1}^{J} \bar{E}_{j t}=\bar{E}_{t}
$$

By setting $\bar{E}$, we represent economy-wide emission reduction targets.

EQUILIBRIUM.- The definition of the equilibrium for the decentralized economy is standard and provided in Appendix A.A1.

\section{Planner's Problem: First-best Policy}

The planner's problem is to maximize social welfare (2) subject to final good production (5), sectoral production (6), market clearing conditions for labor and capital (8), aggregate capital accumulation (9), the resource constraint (10), and attaining the economy-wide emissions constraint $\sum_{j} E_{j t}=\bar{E}_{t}$. The planner's firstorder conditions (FOCs) with respect to the use of sectoral emissions $\left(E_{j t}\right)$ require that the social marginal costs and benefits of using carbon emissions be equated

5In terms of our model, we thus use "carbon emissions" and "fossil energy" interchangeably. 
for every $j$ (see Appendix A.A2):

$$
\underbrace{\mu_{j t}}_{\begin{array}{c}
\text { marginal value } \\
\text { of sectoral output }
\end{array}} \underbrace{\frac{\partial Y_{j t}}{\partial E_{j t}}}_{\begin{array}{c}
\text { marginal product of } \\
\text { sectoral emissions }
\end{array}}=\underbrace{\lambda_{t}^{E}}_{\begin{array}{c}
\text { marginal social cost of } \\
\text { economy-wide emissions }
\end{array}}
$$

It is thus straightforward to see that in the social optimum sectoral carbon prices are uniform.

To see that in a decentralized market economy uniform sectoral carbon prices can achieve the socially optimal outcome, combine the planner's FOCs with respect to consumption $C_{t}$, capital $K_{t+1}$, and investment $I_{t}$ to obtain the planner's Euler equation:

$$
U_{C t}=\frac{1}{1+\zeta_{S}} U_{C t+1}\left(1+R_{t+1}\right) .
$$

Comparing the planner's optimality conditions with those governing the behavior of households (4) and firms (7) in decentralized equilibrium, it is straightforward to show that the first-best allocation can be decentralized by a combination of uniform sectoral carbon prices according to:

$$
\underbrace{p_{j t}}_{\begin{array}{c}
\text { price of } \\
\text { sectoral output }
\end{array}} \underbrace{\frac{\partial Y_{j t}}{\partial E_{j t}}}_{\begin{array}{c}
\text { marginal product of } \\
\text { sectoral emissions }
\end{array}}=\tau_{j t}=\underbrace{\tau_{t}}_{\begin{array}{c}
\text { marginal social cost of } \\
\text { economy-wide emissions }
\end{array}} \forall j,
$$

where $\tau_{t}=\lambda_{t}^{E} / U_{c t}$ and a capital income subsidy to equate the social and private marginal returns on savings:

$$
\Xi_{t+1}=\frac{\zeta_{s}-\zeta}{1+\zeta_{S}} \frac{1+R_{t+1}}{R_{t+1}} .
$$

The intuition behind this result is that private households are too impatient from the planner's perspective, and consequently subsidies on capital are desirable to increase returns to savings to avoid households failing to invest sufficiently in the economy's capital stocks. This result has been shown previously by von Below (2012) and Barrage (2018). Importantly, in a first-best setting in which capital income subsidies can be optimally chosen, optimal sectoral carbon prices are uniform.

\section{Qualitative Results}

\section{A. Constrained-optimal Carbon Prices}

In reality, however, capital income as a whole is taxed and not subsidized. Moreover, climate policy is usually pursued separately from fiscal policy; in particular, it is not directly linked to policy decisions on capital taxation. We thus argue that 
the relevant perspective for carbon pricing policy is to assume that capital income as a whole cannot be subsidized. For the remainder of the analysis, we therefore assume that capital income subsidies are not available and focus on a climate policy which is concerned with choosing constrained-optimal carbon prices.

To analyze carbon pricing in a setting which rules out capital income subsidies, we can re-state the no-subsidy constraints $\Xi_{t} \geq 0$ in terms of the households' intertemporal optimality conditions (4) as:

$$
\left.\frac{U_{C t}(1+\zeta)}{U_{C t+1}} \leq\left(1+R_{t+1}\right)\right), \quad R_{t+1}=M P K_{j t+1}-\delta_{j}, \quad \forall j, \text { and } t>0 .
$$

$M P K_{j t}$ denotes the marginal product of capital in sector $j$ which corresponds to the price for sectoral capital $\left(r_{j t}\right)$ in the decentralized equilibrium. The constrained policy problem is given by adding (17) to the social planner's problem (see Appendix A.A3). Comparing the constrained planner's optimality conditions with those governing the behavior of households and firms in the decentralized equilibrium, it is straightforward to show that:

PROPOSITION 1: In a second-best setting when capital income subsidies are not feasible $\left(\Xi_{t}=0\right)$, the constrained-optimal allocation can be decentralized by sectorspecific carbon taxes which are implicitly defined by equating the marginal benefits of emissions use with the marginal social cost of emissions which comprise a Pigouvian and a social discounting externality-correcting term:

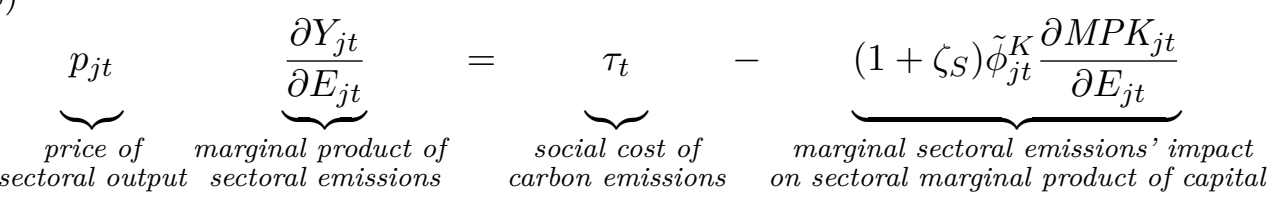

where $\tilde{\phi}_{j t}^{K}=\phi_{j t}^{K} / U_{C t}$ denote the social costs of constrained capital prices that are governed by the private Euler equation.

PROOF: See Appendix A.A3.

Proposition 1 implies that in an economy which endorses social discounting and cannot subsidize capital income may want to impose sectoral $\mathrm{CO}_{2}$ prices which deviate from the Pigouvian carbon tax, where the latter is given by the marginal social cost of economy-wide carbon emissions $\left(\tau_{t}=\lambda_{t}^{E} / U_{c t}\right)$. Intuitively, this is because the planner cares about the overall level of assets given to future generations and consequently takes into account the general equilibrium effects of sectoral carbon taxes on households' savings behavior. Without a capital income subsidy, private savings are not optimal. Consequently, climate policy's impacts on private investment can now have first-order welfare effects. Mathematically, if $\zeta>\zeta_{s}$, the no-subsidy constraint is binding $\left(\phi_{j t}^{K}>0\right)$, the Pigouvian carbon tax is corrected by a term which reflects how reductions in sectoral emissions affect the sectoral marginal product of capital $\left(\partial M P K_{j t} / \partial E_{j t}\right)$. Intuitively, this is because the sectoral $\mathrm{CO}_{2}$ prices are used to bring savings closer to the socially optimal 
path in the presence of the social discounting externality. ${ }^{6} \partial M P K_{j t} / \partial E_{j t}$ reflects the substitutability (complementarity) between capital and emissions inputs in a given sector. For heterogeneous sectoral technologies, the $\partial M P K_{j t} / \partial E_{j t}$ terms vary across sectors, implying that contrained-optimal $\mathrm{CO}_{2}$ prices differ across sectors.

\section{B. When is a Uniform $\mathrm{CO}_{2}$ Price Optimal?}

Before we further investigate the role of technology heterogeneity for multi-sector carbon pricing, it is useful to illustrate the conditions that lead to a uniform carbon price. Given the importance of the established wisdom in environmental economics that a uniform carbon price across different emission sources is efficient, this helps to reveal the implicit assumptions behind this result.

The following result follows straightforwardly from Proposition 1:

PROPOSITION 2: Constrained-optimal sectoral carbon prices are uniform if the economy displays at least one of the following characteristics:

(i) sectoral production technologies are identical,

(ii) the capital stock is exogenously given and fixed, or

(iii) there is no social discounting, i.e. social and private market discount rates coincide $\left(\zeta_{S}=\zeta\right)$.

Proposition 2 highlights the three fundamental premises which underlie the standard perspective often inherent in economic assessments (and models) to study price-based climate change policies. It has important implications for the modelbased evaluations of climate policy in the literature.

Integrated assessment models (Nordhaus, 2007; Barrage, 2018) primarily adopt a single-output framework. ${ }^{7}$ This, however, overlooks relevant heterogeneity at the sectoral level in terms of differences in carbon emission intensity and substitutability between capital and energy inputs in production. As emissions (reductions) and capital are bound together, the optimal use of carbon pricing needs to take into account how a carbon price affects the marginal product of capital in different sectors (see $\partial M P K_{j t} / \partial E_{j t}$ in equation (18)). When social discounting plays a role, the single-sector perspective is only inconsequential for the optimal carbon pricing rule when technology heterogeneity is "negligible", i.e. when sectors are largely identical. In fact, by model construction, such models assume that the optimal $\mathrm{CO}_{2}$ is uniform. To the extent better carbon pricing policies are overlooked, they overstate the costs of climate policy.

Economic models which adopt a richer multi-sector perspective are often static (Böhringer, Carbone and Rutherford, 2016; Landis, Rausch and Kosch, 2018) or assume myopic economic agents ruling out that expectations affect the future capital

\footnotetext{
${ }^{6}$ Without exploring the implications for differentiated $\mathrm{CO}_{2}$ prices, Barrage (2018) and Belfiori (2017) show in a one-sector integrated assessment model that constrained-optimal carbon price reflects the discounted sum of marginal climate damages, corresponding to $\lambda_{t}^{E}$ in our framework, and the general equilibrium effects on the households' savings decisions.

${ }^{7}$ The general model of Golosov et al. (2014) considers multiple energy-producing technologies, but no further sectoral detail below the final goods sector.
} 
stock - for example, models used for climate policy assessments by the European Commission (Capros et al., 2013) and in the academic community (Paltsev et al., 2005; Fawcett et al., 2014; Thompson et al., 2014). This amounts to holding fixed the capital stock or simplifying intertemporal decision rules in a way which also boils down to assuming that a uniform carbon price is optimal. Then, the rationale to differentiate carbon prices according to Proposition 1 vanishes and the optimal carbon price for each sector is equal to the (uniform) Pigouvian level. Proposition 2 (ii) also implies that the partial equilibrium intuition of uniform cost-effective emissions pricing, which by construction ignore effects on capital income, does not carry over to a general equilibrium setting.

Finally, if private agents discount with the same rate as the social planner, there is no need to incentivize households' savings beyond the market remuneration. Hence, $\phi_{j t}^{K}=0$ in (18) and carbon emissions in all sectors are priced uniformly according to the Pigouvian principle $\left(\tau_{j t}=\tau_{t}=\lambda_{t}^{E} / U_{c t}, \forall j\right)$, regardless of whether sectors are heterogeneous or not.

In summary, accepting the social discounting perspective and the (empirical) fact that capital income is not subsidized, the assumptions leading to the conventional climate policy recommendation of a uniform $\mathrm{CO}_{2}$ price are quite stark: either all sectoral outputs in an economy must be produced with identical technologies or intertemporal economic choices must be ignored.

\section{Optimal Sectoral $\mathrm{CO}_{2}$ Prices: The Role of Technology Heterogeneity}

This section investigates multi-sector carbon pricing when sectoral production technologies are heterogeneous. ${ }^{8}$

Based on Proposition 1 and steady-state FOCs, the rule for efficient pricing of carbon emissions in sector $j$ can then be expressed in terms of technology parameters (see Appendix A.A4 for derivation):

$$
\tau_{j}=\underbrace{\tau}_{\begin{array}{c}
\text { social cost of } \\
\text { carbon emissions }
\end{array}} \times \underbrace{\frac{1}{1-\bar{\phi}_{j} \rho_{j} \theta_{j}^{K}}}_{\begin{array}{c}
\Gamma_{j}:=\text { sector-specific correction factor } \\
\text { to account for social discounting externality }
\end{array}}
$$

where $\bar{\phi}_{j}=\left(1+\zeta_{S}\right) \tilde{\phi}_{j}^{K} K_{j}^{-1}$ incorporates the additional cost imposed by deviating from the socially optimal path of capital accumulation as a result of the no-capital income subsidy constraint, or, expressed equivalently, due to requiring that capital prices are governed by the private, but not the social, Euler equation. $\theta_{j}^{K}$ denotes the value share of capital in the capital-emissions bundle in the production of sectoral output $j$ according to (6).

PROPOSITION 3: If sectoral production technologies are heterogeneous, the constrained optimal carbon prices differ across sectors: $\tau_{j} \neq \tau_{k}, \forall j, k$. In particular,

\footnotetext{
${ }^{8}$ We assume throughout that the social planner equally weighs current and future (unborn) generations, implying that the social discount rate is zero. $\zeta_{S}=0$ also enables us to focus on steady-state equilibrium and to derive closed-form solutions.
} 
$\tau_{j}>\tau_{k}$ if ceteris paribus:

(i) capital is a better substitute for emissions in sector $j$ relative to sector $k$ $\left(\rho_{j}>\rho_{k}\right)$,

(ii) the capital share is higher in sector $j$ relative to sector $k\left(\beta_{K j}>\beta_{K k}\right)$ if both sectors are substitutes $\left(\rho_{j}=\rho_{k}>0\right)$ and vice versa if both sectors are complements $\left(\rho_{j}=\rho_{k}<0\right)$,

(iii) capital is more productive $\left(H_{K j}>H_{K k}\right)$ or emissions are less productive $\left(H_{E j}<H_{E k}\right)$ in sector $j$ relative to sector $k$, if both sectors are complements $\left(\rho_{j}=\rho_{k}<0\right)$, and vice versa if both sectors are substitutes $\left(\rho_{j}=\rho_{k}>0\right)$, or

(iv) the capital depreciation rate is lower in sector $j$ relative to sector $k\left(\delta_{j}<\delta_{k}\right)$ if both sectors are substitutes $\left(\rho_{j}=\rho_{k}>0\right)$ and vice versa if both sectors are complements $\left(\rho_{j}=\rho_{k}<0\right)$.

PROOF: See Appendix A.A4.

The important insight from Proposition 3 is that - in an environment where the planner adopts a social discounting perspective and capital income subsidies are not feasible - technology heterogeneity provides an economic rationale for differentiating carbon prices across sectors. Sectoral carbon pricing is a means to influence household savings and move the economy closer to the social optimum. Intuitively, the efficient pattern of sectoral carbon taxes depends on how the amount of capital employed in each sector - and thus the marginal productivity of capital - reacts to the pricing of emissions. This, in turn, hinges on the production technology in each sector, i.e. the way in which profit-maximizing inputs of capital and emissions are combined to produce final goods for consumption.

If sectoral production technologies are identical, the quantity of capital employed in each sector is equally affected by a carbon price. Hence, a uniform carbon price is sufficient to implement the constrained social optimum - simply restating Proposition 2. Also, technology heterogeneity does not matter if there is no social discounting as it is then efficient to price emissions in each sector with the uniform social cost of carbon $\tau .{ }^{9}$

One important aspect of technology heterogeneity relates to the substitutability or complementarity between capital and emissions in sectoral production. Proposition $3(i)$ shows that, everything else being equal, it is optimal to price carbon emissions at a higher rate in sectors which can more easily substitute between capital and emissions. Consider the extreme case in which capital and emissions are perfect complements in one sector and highly substitutable in another sector. A uniform carbon price can then not be optimal and lowering the carbon tax in the "complement" sector increases capital demand in this sector. To compensate for higher emissions (given the fixed economy-wide emissions target), the carbon price in the "substitute" sector has to increase. To the extent that capital and emissions are substitutes, this triggers a substitution away from emissions towards capital

\footnotetext{
${ }^{9}$ This can also be inferred from the sectoral carbon pricing rule in (19). Without social discounting, $\bar{\phi}_{j}=0, \forall j$, implies $\Gamma_{j}=1, \forall j$.
} 
in the "substitute" sector. As output in the "substitute" sector, which now faces a higher carbon tax, falls, the amount of capital used in the "substitute" sector may fall. When capital in this sector is a strong enough substitute for emissions, the reduction in capital use in the "substitute" sector is smaller than the increase in capital use in the "complement" sector. Overall, the differentiation of sectoral carbon taxes leads to an increased use of capital in the economy, thus pushing the economy on a path with higher capital accumulation relative to the case with uniform carbon pricing. Put differently: with uniform carbon pricing, households invest too little and the (steady-state) consumption level is sub-optimally low. This is because savings decisions only take into account private discounting. It is thus optimal for climate policy to tax carbon in a way which boost households' savings by implicitly subsidizing capital, or, steering the relative price of capital to $\mathrm{CO}_{2}$ emissions. The efficient pattern of implicit capital subsidies is inversely related to the elasticity of capital use in each sector: subsidize capital less (tax carbon more) in sectors where capital and emissions are "good" substitutes and subsidize capital more (tax carbon less) in sectors where capital and emissions are "bad" complements.

A similar logic applies if sectoral heterogeneity encompasses other aspects of technology which imply that the adjustment of capital (and emissions) inputs with respect to climate policy differs across sectors. Even if capital and emissions inputs are identical in terms of their degree of substitutability (same $\rho$ 's across sectors), a sector with a high capital share $\left(\beta_{K}\right)$ should receive a higher sectoral carbon tax as compared to a sector with a low share of capital if both sectors are substitutes (see Proposition $3(i i)$ ). The reason is that a sector with a higher share of capital can more easily substitute between capital and emissions (provided that $\rho>0$ ). This is also the case if the productivity of capital in a sector is higher $\left(H_{K}\right)$ or if capital in a sector depreciates at a lower rate $(\delta)$ - see Proposition $3($ iii $)$ and $(i v)$. In all cases, it is efficient to tax carbon emissions in this sector at a higher rate as compared other to sectors with a lower $\beta_{K}$ or $H_{K}$, or a higher $\delta$, as such a carbon tax differentiation increases investments and economy-wide capital stock, and in turn future consumption and welfare while achieving the same level of carbon emissions.

SPECIAL CASE OF COBB-DOUGLAS TECHNOLOGIES.- It is important to emphasize that the frequently assumed case of Cobb-Douglas production functions entirely mutes the role of technology heterogeneity for carbon price differentiation:

PROPOSITION 4: If production technologies in all sectors are Cobb-Douglas $\left(\rho_{j}=\right.$ $0, \forall j)$, constrained-optimal sectoral carbon prices are uniform.

PROOF: For $\rho_{j}=0, \forall j: \lim _{\rho_{j} \rightarrow 0} \partial \mathrm{MPK}_{j} / \partial E_{j}=\lim _{\rho_{j} \rightarrow 0}-\rho_{j} \theta_{j}^{K} K_{j}^{-1} \tau_{j}=0$, and it follows from (18) that $\tau_{j}=\tau$.

Cobb-Douglas technologies imply that each input factor has a constant value share relative to final output. Carbon pricing then causes inputs of emissions and capital to change equally across sectors, and the motive for differentiating sectoral $\mathrm{CO}_{2}$ prices to increase the economy-wide capital stock disappears. 
TABLE 1. Overview of key parameter values for model calibration

\begin{tabular}{|c|c|c|c|c|}
\hline \multirow[t]{2}{*}{ Parameter } & \multicolumn{4}{|c|}{ Model sector $j$} \\
\hline & Electricity & Industry & Transport & Services \\
\hline Capital rental rate $\left(r_{j}\right)$ & 0.14 & 0.20 & 0.10 & 0.10 \\
\hline Baseline carbon price $\left(\tau_{j}\right)\left[€\right.$ per ton of $\left.\mathrm{CO}_{2}\right]$ & 30 & 30 & $\approx 0$ & $\approx 0$ \\
\hline Share share of sectoral output in final output $\left(\gamma_{j}\right)$ & 0.04 & 0.21 & 0.05 & 0.70 \\
\hline Share share of $\mathrm{L}$ versus K-E aggregate $\left(\alpha_{j}\right)$ & 0.29 & 0.65 & 0.63 & 0.61 \\
\hline Share share of $\mathrm{K}$ in $\mathrm{K}-\mathrm{E}$ aggregate $\left(\beta_{K j}\right)$ & 0.76 & 0.83 & 0.99 & 0.99 \\
\hline \multicolumn{5}{|l|}{ Substitution elasticity between K-E in $Y_{j}\left(\rho_{j}\right)$} \\
\hline All complements (central case) & -0.50 & -5.00 & -1.00 & -4.00 \\
\hline All substitutes & 0.40 & 0.10 & 0.30 & 0.20 \\
\hline Substitutes $\&$ complements & 0.40 & -5.00 & 0.15 & -1.00 \\
\hline Strong substitutes $\&$ complements & 0.50 & -8.00 & -1.00 & -6.00 \\
\hline
\end{tabular}

Notes: Parameter values are selected based on the following information. $r_{j}$ : based on the World InputOutput Database (WIOD, Timmer et al., 2015). $\tau_{j}$ : chosen values intend to portray an average carbon price over the period 2010-2020 in the EU ETS. To enable the calculation of a positive value shares for carbon for the transport and services sectors, which have so far not been subject to (explicit) carbon pricing under the EU ETS, we choose a very small but positive value for $\tau_{j}$ for these sectors. $\gamma_{j}$ and $\alpha_{j}$ : value share parameters based on WIOD. $\rho_{j}$ : parameters describing the substitution between capital and energy are taken from the literature (for references, see text).

\section{Quantitative Model and Calibration}

To explore the relevance of our theoretical results in an empirical context, we use a steady-state version of the model described in Section I calibrated to the current EU economy. Appendix A.A5 provides the steady-state conditions.

To capture technological heterogeneity, we decompose the main economic sectors and integrate empirical estimates regarding the sector-specific substitutability of capital and energy. The sectoral disaggregation is driven by the following considerations: we want to identify sectors which are responsible for the majority of $\mathrm{CO}_{2}$ emissions in a typical industrialized economy as the EU, exhibit differences in capital emissions intensities, and are either subject to carbon pricing policies, for example, the EU ETS, or not. We distinguish the following sectors $j \in J=\{E, I, T, S\}$ : electricity $(E)$, energy-intensive industries $(I)$, transportation $(T)$, and services $(S) \cdot{ }^{10}$

Given policy choices on $\Xi=0$ and $\tau_{j} \geq 0$, we need to pin down the following parameters to calibrate a steady-state model: $\left(\alpha_{j}, \gamma_{j}, \delta_{j}, \zeta, \rho_{j}, \beta_{K j}, H_{K j}, H_{E j}, \bar{L}\right)$. We select these parameters to capture the structure of the aggregated EU economy with respect to (i) the sectoral composition of output, (ii) the mix of capital, labor, and emissions input, and (iii) the observed savings rate. All parameter values are found from data targets without the need to simulate the model. Table 1 summarizes the parametrization for the central case of the model.

\section{A. External Parameters}

To parametrize $\gamma_{j}$ and $\alpha_{j}$, we use two data sources. First, we obtain the value of sector-specific inputs of employment and capital from the WIOD (World Input-

\footnotetext{
${ }^{10}$ We do not explicitly include agriculture as a separate sector as it only accounts for a small share of $\mathrm{CO}_{2}$ emissions. It is beyond the scope of this paper to include emissions from non- $\mathrm{CO}_{2}$ greenhouse gases.
} 
Output Database, Timmer et al., 2015). WIOD contains information at the country level, and we aggregate the data to the EU-28. We use data for the most recent available year 2014. We use the Standard Industrial Classification, Revision 4, to map WIOD categories to the four model sectors according to the mapping shown in Appendix B. For European countries outside of the Euro zone, we apply exchange rate data from OECD (2020). Second, we obtain information on $\mathrm{CO}_{2}$ emissions at the sectoral level from the European Commission's EDGAR database (Emission Database for Global Atmospheric Research, Crippa et al., 2019) and link emissions from fossil-fuel combustion as well as process emissions to the sectors using the mapping shown in Appendix B. In order to compute value shares, we need to complement emissions data with an assumption about the costs of carbon emissions at the sectoral level. For the $P$ and $I$ sectors, which are subject to EU ETS regulation, we assume a carbon price of $\tau_{P}=\tau_{I}=30 €$ per ton of $\mathrm{CO}_{2}$. The $T$ and $S$ sectors are not subject to EU ETS regulation, and we assume a carbon price of zero. We set $H_{K j}=H_{E j}=1, \forall j$, as we cannot separately identify $H$ and $\beta$ from the data. Using the information on the value of inputs for $K, L$, and $E$ for each sector, we can infer $\gamma_{j}$ and $\alpha_{j}$.

We survey the literature (Koesler and Schymura, 2015; Okagawa and Ban, 2008; van der Werf, 2008; Costantini, Crespi and Paglialunga, 2019; Dissou, Karnizova and Sun, 2015; Papageorgiou, Saam and Schulte, 2017) to pin down reasonable values for $\rho_{j}$. First, complementarity is the highest in the industry and services sectors (with lower estimates ranging from -6.96 to -2.33 and higher estimates ranging from -1.56 to 0 ). Second, the power and transportation sectors seem to exhibit a small degree of complementarity (with lower estimates ranging from -1.70 to -1.22 and upper estimates ranging from -1.17 to 0.21 ).

Given the uncertainty of empirical estimates and the central role of sectoral technology heterogeneity for our analysis, we consider four different cases representing different assumptions about the substitutability between capital and energy (emissions) input in sectoral production. "All complements" assumes that $\rho_{j}<0$ for all sectors, reflecting a case where the substitutability between capital and energy inputs is limited. "All substitutes" represents a case with high substitutability. The other two cases ("Substitutes \& complements" and "Strong substitutes \& complements") represent intermediate cases where capital and energy inputs are (strong) complements in some sectors and (strong) substitutes in others.

\section{B. Calibrated Parameters}

Using the steady-state no-arbitrage condition (i.e., $\delta_{j}=r_{j}-\zeta$ ) and data on $r_{j}$ from WIOD (taking the value for 2014), we determine $\zeta$ and $\delta_{j}$. To obtain $r_{j}$, we divide the total sectoral capital compensation by the sectoral nominal capital stock employed. We calibrate the private discount rate of $\zeta$ by targeting an aggregate savings rate of 22 percent for the EU-28 (World Bank, 2020). The savings rate is related to capital depreciation according to $\sum_{j} \delta_{j} K_{j} / \hat{Y}$. We obtain $\zeta=0.0475$. Given $\zeta$, we infer sector-specific depreciation rates $\delta_{j}$. As labor is exogenous and enters in a Cobb-Douglas manner in sectoral production, we can normalize $\bar{L}=1$. 
Given $\rho_{j}$ and $\tau_{j}$, and using data on emissions from EDGAR and on the value of capital inputs and rental prices by sector from WIOD, we calibrate $\beta_{K j}$ based on combining the FOCs for profit-maximizing inputs of capital and emissions in each sector.

\section{The Computational Experiment}

To obtain insights into the nature of optimal multi-sector carbon pricing and associated welfare gains, we interact three dimensions in our simulations: the structure of sectoral $\mathrm{CO}_{2}$ pricing $(\mathcal{S})$, policy stringency $(\mathcal{P})$, and technology heterogeneity $(\mathcal{H})$.

STRUCTURE OF $\mathrm{CO}_{2}$ PRICING.-We consider three cases that differ in terms of the permissible structure of sectoral $\mathrm{CO}_{2}$ prices: $s \in \mathcal{S}=\{$ Optimal, Uniform, Partitioned Pricing\}. These cases cover the theoretical case of "optimal" pricing, where carbon prices $\tau_{j}$ are optimally differentiated across sectors (corresponding to a numerical evaluation of (18) in Proposition 1), and the case of uniform pricing which reflects "conventional" policy recommendation. An intermediate case represents a situation where sectoral $\mathrm{CO}_{2}$ prices can only be partially differentiated because they are constrained by the presence of disintegrated carbon markets or multiple ETSs within a jurisdiction.

POLICY STRINGENCY.-We vary climate policy stringency to examine how the multi-sector carbon pricing depends on the economy-wide emissions budget. ${ }^{11} \mathrm{We}$ consider economy-wide emissions reductions of up to $80 \%$ (relative to a 2014 baseline emissions level): $p \in \mathcal{P}=\{0,20,40,60,80\} .{ }^{12}$

HETEROGENEOUS CAPITAL-ENERGY SUBSTITUTABILITY.- Technology heterogeneity in terms of the substitutability (complementarity) between capital $K$ and energy (emissions) $E$ inputs in sectoral production is the key driver of our main result that a uniform carbon price is not optimal (see Propositions 2 and 3). An important aspect of our computational experiment is examine the role of technology heterogeneity for multi-sector carbon pricing. We consider four cases ranging from "poor" to "high" K-E substitutability: $h \in \mathcal{H}=\{$ All complements, All substitutes, Substitutes \& complements, Strong substitutes\& complements $\}$ as defined in Section III and Table 1.

MEASURING WELFARE GAINS.-We measure the economic cost of climate policy as:

$$
\Gamma_{h, p}^{s}:=\frac{C_{h, p}^{s}}{C_{h, 0}^{s}}-1
$$

where $C_{h, p}^{s}$ is the steady-state aggregate consumption level. We calculate the reduction in the welfare cost of climate policy due to "Optimal" relative to "Uniform"

\footnotetext{
${ }^{11}$ When comparing welfare, we always hold economy-wide $\mathrm{CO}_{2}$ emissions $\bar{E}_{t}$ or, equivalently, emission reductions $\Delta \bar{E}_{t}$, fixed.

${ }^{12}$ The higher targets are in line with the stated ambitions of the European Commission (2020) to reduce greenhouse gas emissions in the EU economy by $55 \%$ in 2030, relative to 1990 levels, and to achieve climate neutrality by mid-century.
} 
carbon pricing as:

$$
\Psi_{h, p}:=\frac{C_{h, p}^{\text {Optimal }}-C_{h, p}^{\text {Uniform }}}{C_{h, p}^{\text {Uniform }}-C_{h, 0}^{\text {Uniform }}} .
$$

\section{Quantitative Results}

\section{A. Multi-Sector vs. Uniform Carbon Pricing: Welfare Gains}

How large are the welfare gains from optimally differentiating carbon prices across sectors relative to uniform carbon pricing? Given the insights from Propositions $1-3$, the answer to this question largely depends on the degree of technology heterogeneity in terms of capital-emissions (K-E) substitutability between sectors.

It is well known that the $\mathrm{K}-\mathrm{E}$ substitutability influences the macroeconomic cost of climate change mitigation policies (see, for example, Weyant et al., 1996; $\mathrm{Lu}$ and Stern, 2016). Thus, to provide context for our analysis, we first report the welfare cost of climate policy with uniform and optimal $\mathrm{CO}_{2}$ pricing by policy stringency $\mathcal{P}$ and for alternative assumptions about technology heterogeneity $\mathcal{H}$ (Figure 1). Panel (a) shows $\Gamma_{h, p}^{\text {Uniform }}$, the welfare cost of achieving a given economy-wide emissions reduction target with uniform carbon pricing for the different cases of technology heterogeneity. Not surprisingly, the cost of climate policy increase more than proportionally with policy stringency, reflecting the increasing cost to substitute emissions for capital - given the CES production technologies in (6). Also, welfare cost is substantially higher if the economy exhibits a "poor" substitutability between capital and energy in production, in particular when the economy-wide emissions reduction target is high.

The main insight from Panel (b) in Figure 1 is that uniform carbon pricing gives away substantial efficiency gains by failing to (optimally) differentiate sectoral $\mathrm{CO}_{2}$ prices. The reduction in the cost of climate policy due to "Optimal" carbon pricing $\left(\Psi_{h, p}\right)$ are up to $50 \%$ relative to "Uniform" pricing. These gains, however, decrease with policy stringency as higher emissions reductions imply that eventually all sectors need to decarbonize substantially, in turn diminishing the scope for efficiency gains by shifting sectoral abatement patterns. Moreover, these gains depend crucially on the degree of technology heterogeneity between sectors. If all sectors exhibit a high substitutability between capital and energy, the welfare gain from differentiating sectoral $\mathrm{CO}_{2}$ prices is low. In contrast, if the economy is composed of sectors with complementary relationships between $\mathrm{K}$ and $\mathrm{E}$ inputs and, in addition, features sectors where $\mathrm{K}$ and $\mathrm{E}$ are substitutes, the reductions in climate policy cost can be substantial, even for high levels of policy stringency.

\section{B. Technology Heterogeneity Matters}

$\mathrm{CO}_{2}$ PRICE DIFFERENTIATION.-We find that the differentiation of $\mathrm{CO}_{2}$ prices across sectors under optimal policy is quantitatively significant.

Figure 2 shows the dispersion of optimal sectoral $\mathrm{CO}_{2}$ prices, the respective mean, and the corresponding uniform carbon price to achieve a given emission 


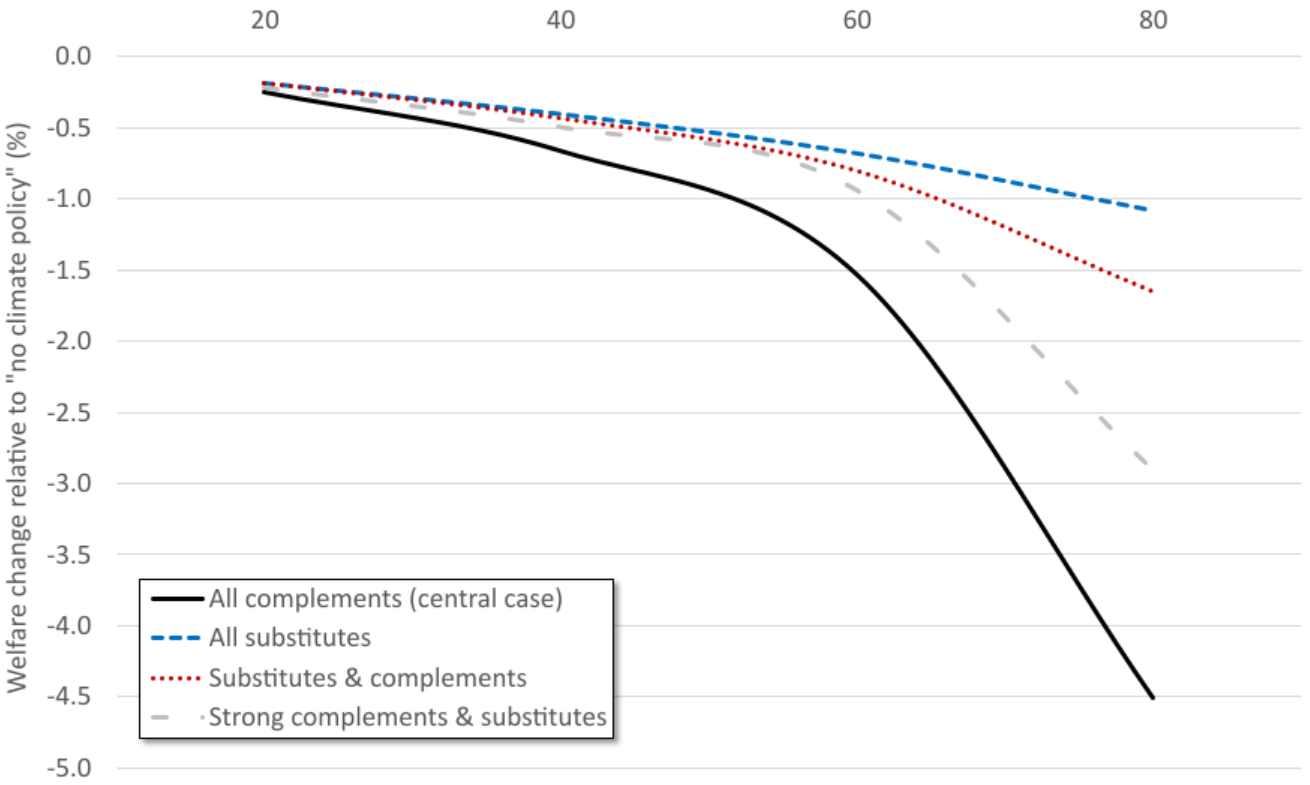

Economy-wide emissions reduction (\%)

(a) Cost of climate policy with uniform carbon pricing $\left(\Gamma_{h, p}^{\text {Uniform }}\right)$

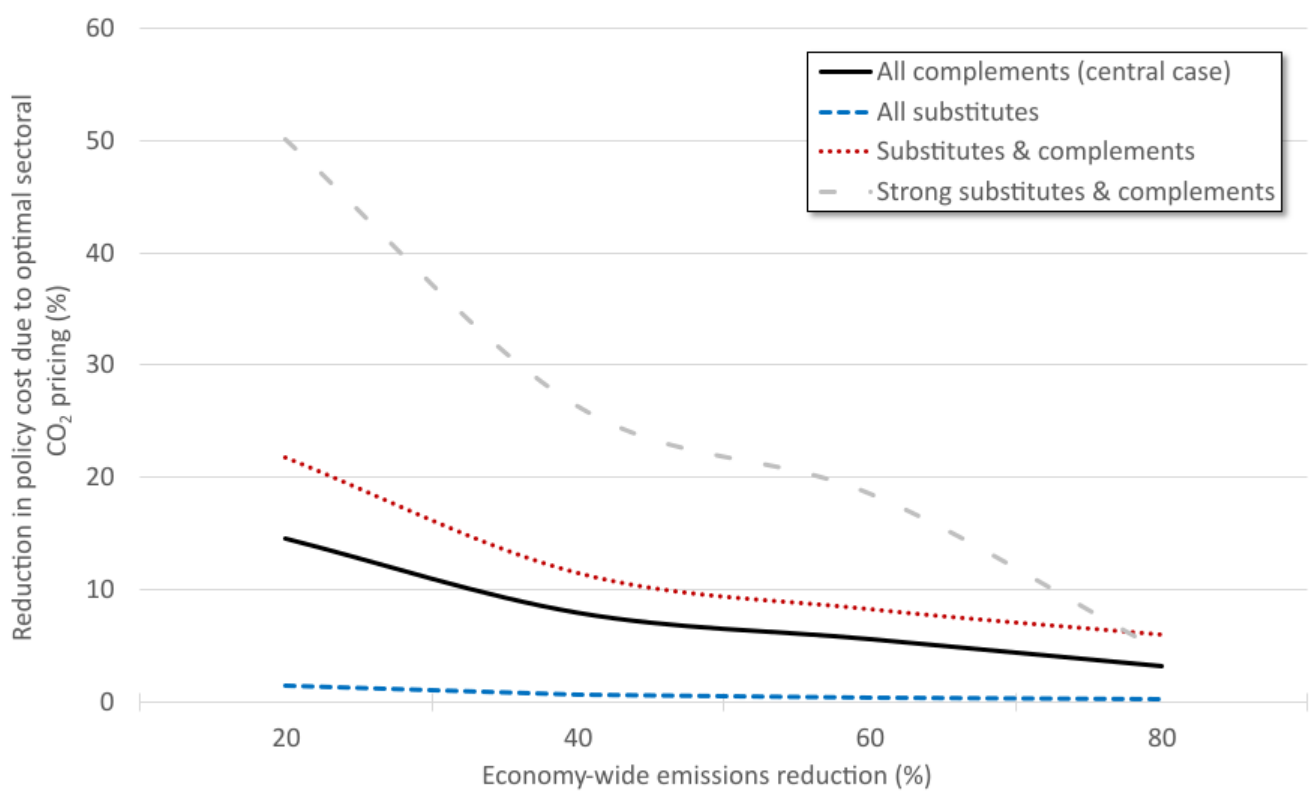

(b) Reduction in cost of climate policy under optimal sectoral relative to uniform carbon pricing $\left(\Psi_{h, p}\right)$

Figure 1 . Welfare cost of climate policy with uniform and optimal $\mathrm{CO}_{2}$ pricing by policy stringency $\mathcal{P}$ and for alternative assumptions about technology heterogeneity $\mathcal{H}$ 


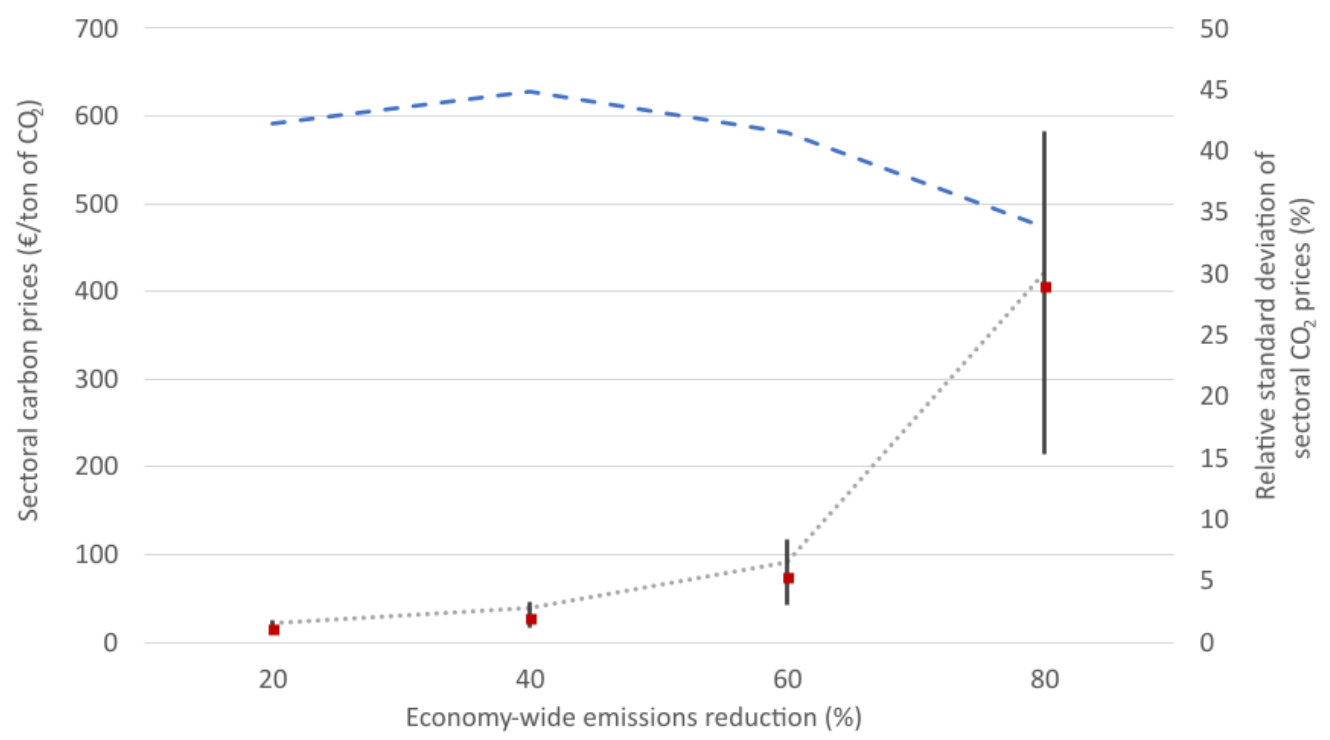

Figure 2. Dispersion of constrained-optimal sectoral $\mathrm{CO}_{2}$ prices $\left(\tau_{j}\right)$, average $\mathrm{CO}_{2}$ price, and uniform carbon price for alternative levels of policy stringency $(\mathcal{P})$

Notes: Results show the dispersion of sectoral $\mathrm{CO}_{2}$ prices (assuming the policy case "Optimal", centralcase technology heterogeneity) is illustrated using the following metrics: Red box = emissions-weighted mean of sectoral prices, Black vertical line $=$ indicates the range of minimum and maximum sectoral $\mathrm{CO}_{2}$ prices; Grey dotted line = uniform $\mathrm{CO}_{2}$ price under the policy case "Uniform"; Blue dashed line (on secondary vertical axis) = coefficient of variation, i.e. the emissions-weighted standard deviation divided by the emissions-weighted mean $\times 100$.

reduction target. For example, for a $40 \%$ economy-wide emissions reduction in the European economy, optimal sectoral prices range from $€ 42.3$ to $€ 116.9$ per ton of $\mathrm{CO}_{2}$, with an emissions-weighted mean $\mathrm{CO}_{2}$ price of $€ 74.4 /$ ton. By comparison, achieving the same emissions target would require a price of $€ 91.3 /$ ton. We also find that the variation in optimal $\mathrm{CO}_{2}$ prices is robust with respect to the economywide emission reduction target: the coefficient of variation of optimal sectoral $\mathrm{CO}_{2}$ prices is roughly constant at $40 \%$ for targets of up to $80 \%$.

Figure 3 reports the deviation of optimal sectoral $\mathrm{CO}_{2}$ prices from uniform carbon pricing. The differentiation of sectoral $\mathrm{CO}_{2}$ prices hinges on (1) the heterogeneity in the $\mathrm{K}-\mathrm{E}$ substitutability between sectors and (2) the complementarity between $\mathrm{K}-\mathrm{E}$ for at least some sectors. First, if $\mathrm{K}-\mathrm{E}$ are "substitutes" in all sectors of the economy, the deviations from a uniform carbon price are negligible. Then, sectoral $\mathrm{CO}_{2}$ pricing has a small effect on capital demand in each sector compared to uniform pricing, implying that differentiated $\mathrm{CO}_{2}$ prices are not very effective in creating an incentive for capital accumulation beyond what is already implied by economic agents' saving decisions based on private discounting. Accordingly, the impact on the aggregate capital stock is small under "All Substitutes" (see Figure 4), consistent with the negligible welfare gains from optimal sectoral $\mathrm{CO}_{2}$ pricing (see Panel (b) in Figure 1). Thus, an overall high K-E substitutability in the economy, as reflected by the case of $\rho_{j}>0$ in all sectors, almost entirely dampens 


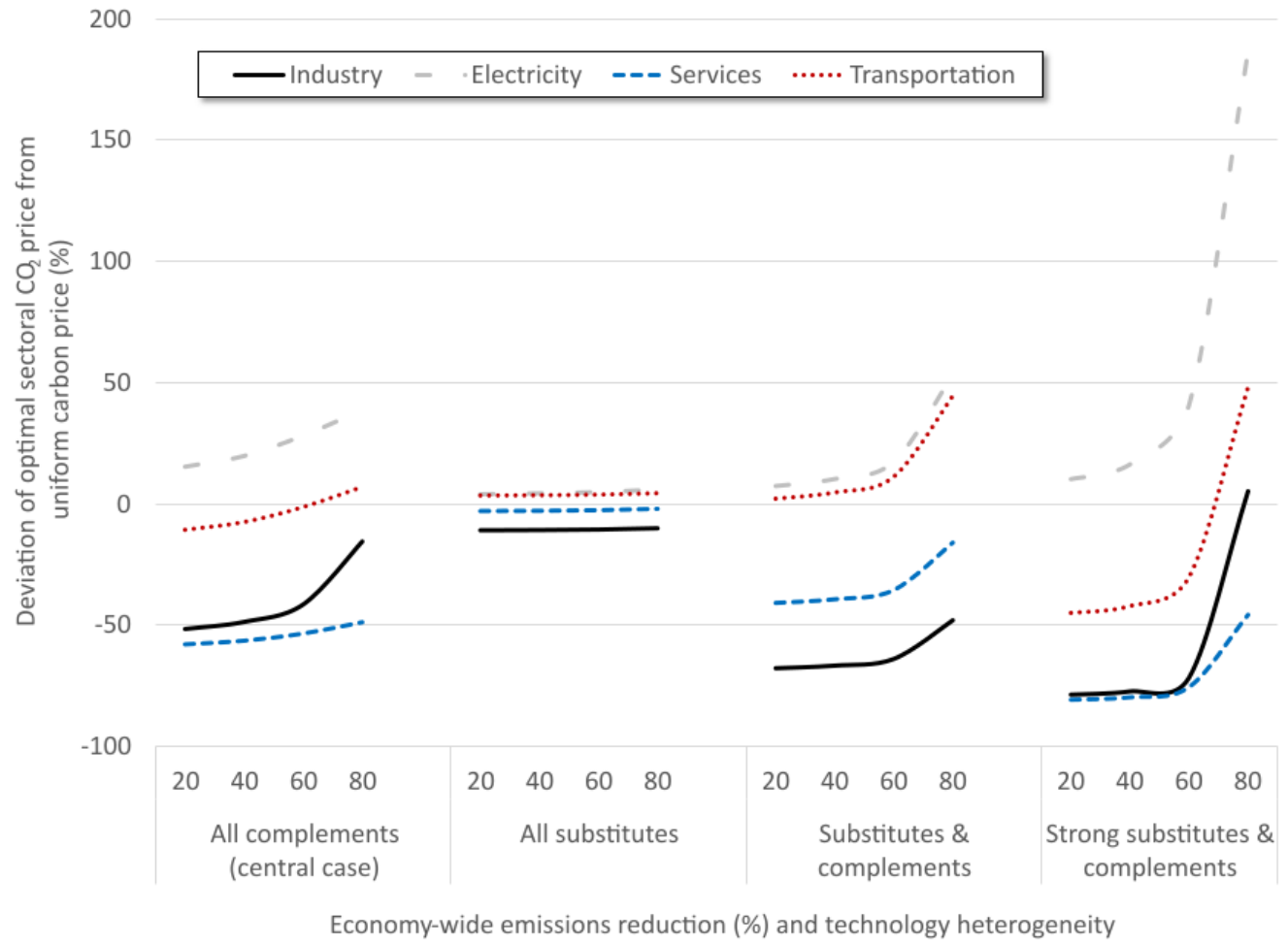

FiguRE 3. Deviation of constrained-optimal sectoral $\mathrm{CO}_{2}$ prices from uniform carbon pricing by policy stringency by technology heterogeneity

the mechanism of using sectoral emission prices to implicitly subsidize capital to address the capital externality resulting from social discounting.

Second, if all sectors are "complements" and differ with respect to the degree of complementarity, differentiating sectoral $\mathrm{CO}_{2}$ provides an effective way of increasing economy-wide capital demand and accumulation. Table 2 complements Figure 3 by showing the absolute level of sectoral $\mathrm{CO}_{2}$ prices in $€ /$ ton of $\mathrm{CO}_{2}$. Carbon is priced at a substantially lower rate in sectors for which the $\mathrm{K}-\mathrm{E}$ substitutability is relatively poor (i.e., $\tau_{\text {Industry }}^{*}$ and $\tau_{\text {Services }}^{*}$ are about half of the $\mathrm{CO}_{2}$ price under "Uniform" emissions pricing and about one third lower than the mean of optimal sectoral carbon prices $\overline{\tau^{*}}$ ). Accordingly, sectoral $\mathrm{CO}_{2}$ prices in "Electricity" and "Transport", which exhibit a higher substitutability between capital and emissions relative to the "Industry" and "Services", exceed the uniform carbon price and $\overline{\tau^{*}}$ considerably.

Third, for a given emissions reduction target, the optimal $\mathrm{CO}_{2}$ pricing policy yields greater welfare gains, the more heterogeneous is the substitutability between capital and emissions among sectors. "Strong substitutes 83 complements" represents the largest degree of technology heterogeneity among the four cases and is associated with the largest gains in aggregate capital and welfare. Here, the optimal pattern of sectoral $\mathrm{CO}_{2}$ price differentiation is such that the comple- 


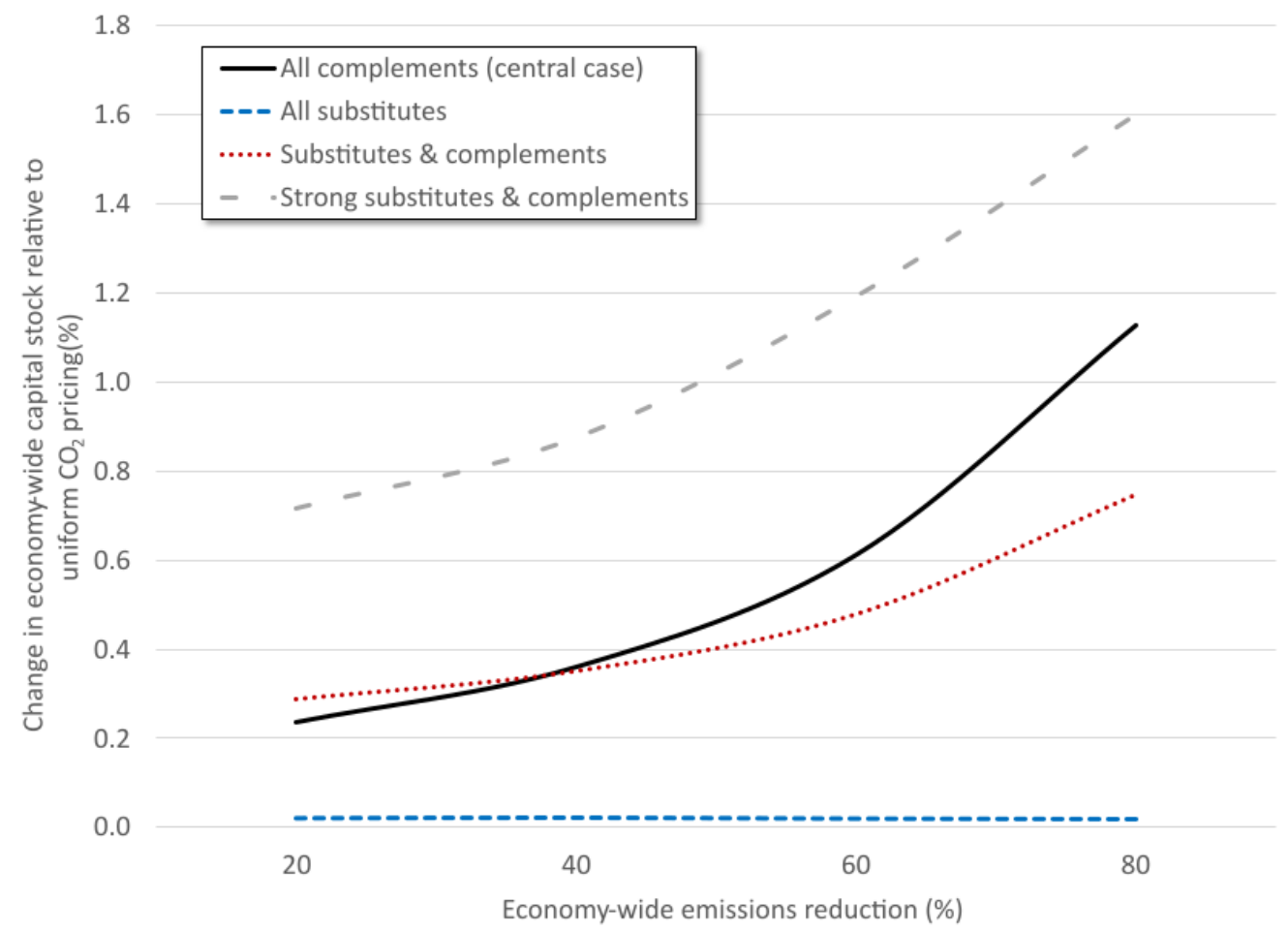

(a) Capital stock $K$

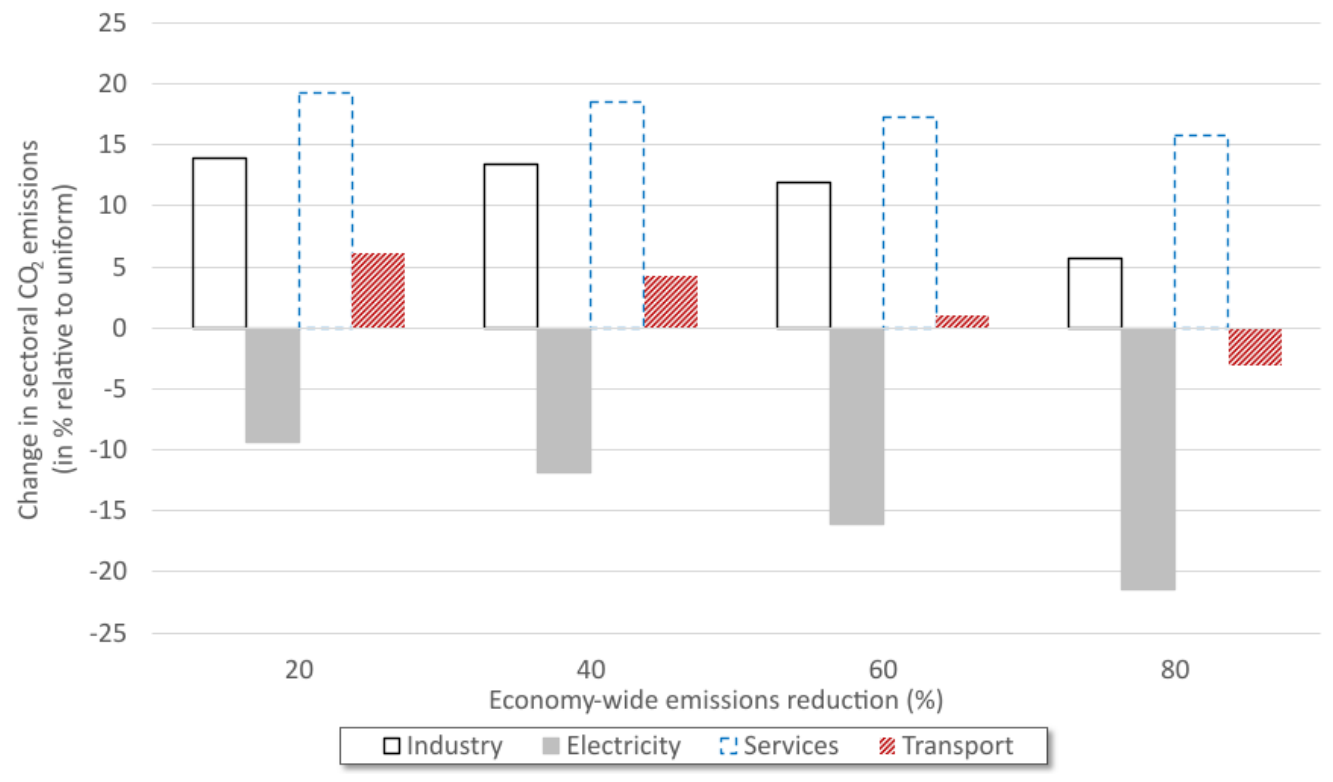

(b) Sectoral $\mathrm{CO}_{2}$ emissions $E_{j}$

FigURE 4. Impacts on steady-state capital stock and sectoral emissions under constrained-optimal sectoral $\mathrm{CO}_{2}$ prices relative to uniform carbon pricing 
TABLE 2. $\mathrm{CO}_{2}$ prices ( $€ /$ ton of $\left.\mathrm{CO}_{2}\right)$ under uniform and constrained-optimal sectoral carbon pricing

\begin{tabular}{|c|c|c|c|c|c|c|}
\hline \multirow{2}{*}{$\begin{array}{l}\text { Policy } \\
\text { target }(\%)\end{array}$} & \multicolumn{5}{|c|}{ "Optimal" sectoral $\mathrm{CO}_{2}$ pricing } & \multirow{2}{*}{$\begin{array}{r}\text { "Uniform" } \mathrm{CO}_{2} \text { pricing } \\
\tau=\tau_{j}, \forall j\end{array}$} \\
\hline & $\tau_{\text {Industry }}^{*}$ & $\tau_{\text {Electricity }}^{*}$ & $\tau_{\text {Services }}^{*}$ & $\tau_{\text {Transport }}^{*}$ & $\overline{\tau^{*} a}$ & \\
\hline 20 & 10.7 & 25.6 & 9.3 & 19.8 & 16.2 & 22.2 \\
\hline 40 & 20.0 & 46.8 & 17.0 & 36.1 & 28.7 & 39.1 \\
\hline 60 & 53.3 & 116.9 & 42.3 & 89.9 & 74.4 & 91.3 \\
\hline 80 & 355.1 & 583.5 & 214.7 & 449.6 & 406.4 & 420.7 \\
\hline
\end{tabular}

Notes: Results shown assume the central-case for technology heterogeneity. ${ }^{a}$ : Emissions-weighted mean of optimal sectoral $\mathrm{CO}_{2}$ prices $\tau_{j}^{*}$.

mentary sectors "Industry" and "Services" each receive a significantly lower price and decrease less relative to the substitution sectors "Electricity" and "Transport". This large heterogeneity in the substitutability between $\mathrm{K}-\mathrm{E}$ implies quite heterogeneous sectoral responses in the sectoral use of capital. Optimal carbon pricing can then exploit this mechanism to incentivize economy-wide capital accumulation with positive welfare effects for future generations.

IMPACTS ON CAPITAL STOCK AND SECTORAL EMISSIONS.-Panel (a) in Figure 4 shows that the capital stock increases when sectoral $\mathrm{CO}_{2}$ prices are optimally differentiation. The more stringent the climate policy, the greater the increase. Intuitively, steering the sectoral use of emissions and indirectly of capital through appropriate sectoral $\mathrm{CO}_{2}$ prices has greater leverage when the economy-wide emissions budget is small. However, the incremental gains from capital accumulation at higher reduction targets are not large enough to overcompensate for the increasing economy-wide costs resulting from the limited substitutability between capital and emissions at the economy-wide level. Regardless of the gains from capital accumulation, therefore, the reduction in the costs of climate policy fall with policy stringency, as shown in Panel (b) in Figure 1.

Consistent with the pattern of sectoral carbon prices, Panel (b) in Figure 4 shows that, more (less) $\mathrm{CO}_{2}$ emissions are abated in the relatively flexible (inflexible) sectors, relative to uniform carbon pricing. This is in line with Proposition 3: allocating more (less) of the economy's aggregate emissions budget to the less (more) flexible sectors spurs additional capital accumulation in the economy consistent with a social perspective that places a higher value on the welfare of future generations than private discounting implies.

\section{Non-Uniform Optimal Carbon Prices: How Convincing?}

While the four cases of technology heterogeneity considered so far are useful to develop an intuition for the conditions under which optimal sectoral $\mathrm{CO}_{2}$ pricing yields quantitatively significant welfare gains (relative to uniform carbon pricing), we next conduct a systematic assessment of the impact of technology heterogeneity.

SYSTEMATIC SENSITIVITY ANALYSIS. - Given the lack of empirical estimates that would characterize the (joint) distribution of the capital-energy substitutability in sectoral production $\left(\rho_{j}\right)$, we adopt the following approach to sample technology heterogeneity. We assume that $\rho_{j}, j \in\{E, I, T, S\}$ are independently and uniformly distributed with support $\left[a_{j}, b_{j}\right]$. We draw a sample of 10'000 sets of 


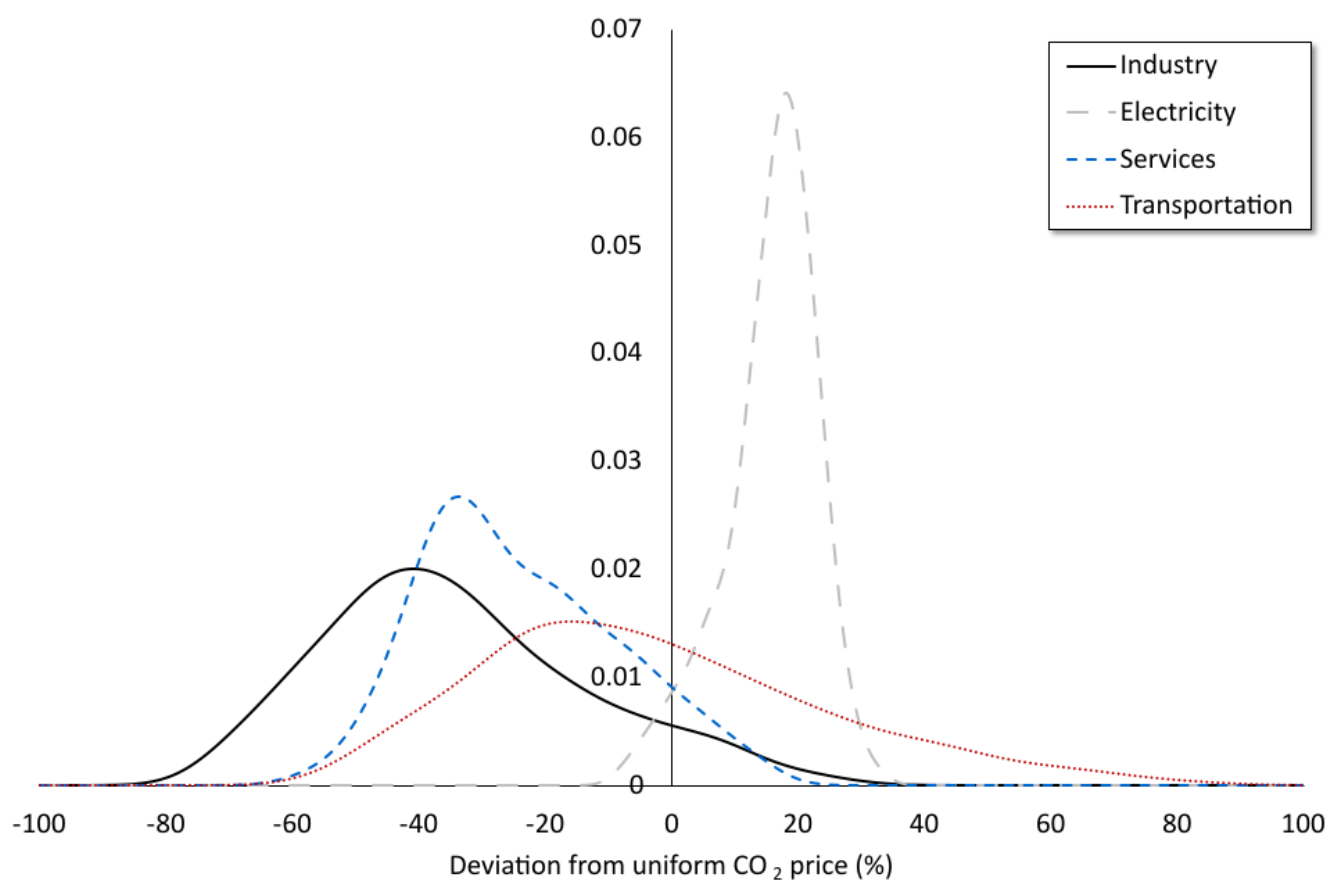

(a) Optimal sectoral carbon prices $\left(\tau_{j}^{*}\right)$ vs. uniform carbon price $(\tau)$ for a $40 \%$ reduction target

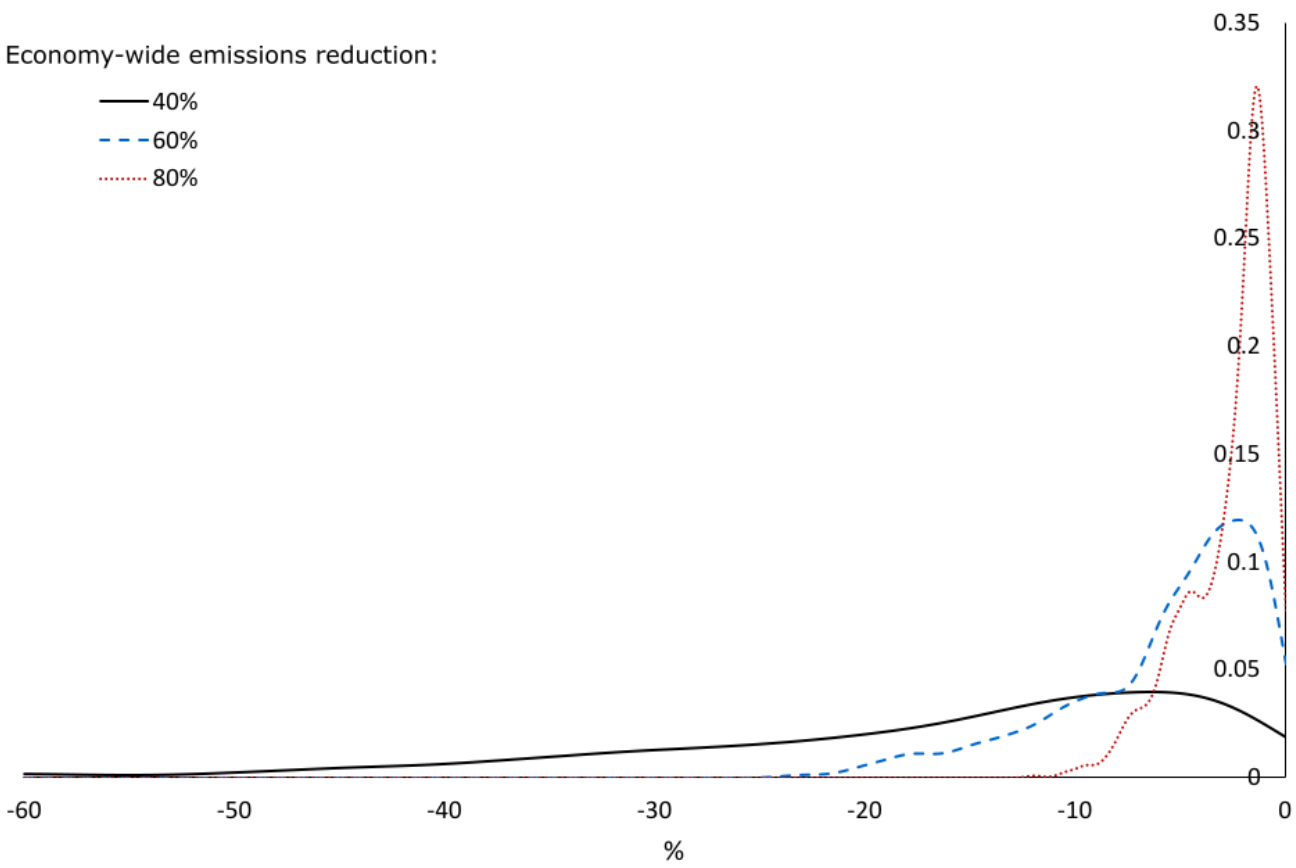

(b) Reduction in policy cost due to optimal sectoral relative to uniform carbon pricing $\left(\Psi_{h, p}\right)$ for alternative levels of emissions reduction

FIGURE 5. Kernel estimation of probability density functions (PDFs) for systematic variation of technology heterogeneity

Notes: Based on Monte-Carlo simulations with 10'000 draws systematically varying the sector-specific capital-energy (emissions) substitutability. Sample mean and standard deviation for PDFs in Panel (a) by sector: "Electricity": (15.7\%, 7.3\%); "Industry": (-34.1\%, 20.9\%); "Transportation": $(-2.9 \%, 27.1 \%)$; "Services": $(-24.0 \%, 15.6 \%)$. Sample mean and standard deviation for PDFs in Panel (b) by emissions reduction target: $40 \%:(-17.4 \%, 0.15 \%) ; 60 \%:(-5.7 \%, 0.10 \%) ; 80 \%:(-2.6 \%, 0.02 \%)$. 
parameter values using our survey of the literature on "piecemeal" estimates for $\rho_{j}$ (see Section III.A). ${ }^{13}$ To decompose the impact of policy stringency, we conduct Monte-Carlo simulations for economy-wide emissions reduction targets of 40,60, and 80 percent, respectively.

ROBUSTNESS OF NON-UNIFORM CO PRICES AND WELFARE GAINS.-Figure 5 shows Kernel density estimations of PDFs for the deviation in optimal sectoral $\mathrm{CO}_{2}$ prices relative to uniform carbon pricing in Panel (a) and the reduction in policy cost from optimal sectoral relative to uniform carbon pricing for alternative economywide emissions reduction targets in Panel (b). The key insight, which supports our previous results, is that both the welfare gains and the extent of $\mathrm{CO}_{2}$ price differentiation significantly differ comparing constrained-optimal to uniform carbon pricing. First, for the given variation in technology heterogeneity, there is a large probability for optimal sectoral $\mathrm{CO}_{2}$ to deviate from the respective uniform carbon price. The two sectors "Industry" and "Services," where K-E substitutability is drawn from distributions with relatively large negative (small positive) values for the lower (upper) bounds, show the highest downward deviation with a mean of $34.1 \%$ and $24.0 \%$ and a standard deviation of $20.9 \%$ and $15.6 \%$, respectively. This is in line with the intuition developed so far that "complement" sectors abate less (i.e., face a lower $\mathrm{CO}_{2}$ price) under optimally differentiated carbon pricing. $\mathrm{CO}_{2}$ emissions in the "Electricity" sector, which is characterized by a relatively large degree of $\mathrm{K}-\mathrm{E}$ substitutability, are in almost all cases priced at a higher rate than under uniform pricing, with a mean and standard deviation of $15.7 \%$ and $7.3 \%$, respectively. The optimal sectoral $\mathrm{CO}_{2}$ price in "Transportation" is lower or higher than under uniform pricing, with a mean and standard deviation of $-2.9 \%$ and $27.1 \%$. Second, the mean reduction in the policy cost from optimal sectoral $\mathrm{CO}_{2}$ pricing is $17.4 \%$ for a $40 \%$ emission reduction target, but drops to $5.7 \%$ and $2.6 \%$ for $60 \%$ and $80 \%$ reduction targets, respectively. While focusing on the mean impact reflects the intuition behind Panel (b) in Figure 1, the PDFs of relative welfare gains show a large dispersion, in particular for smaller emissions reduction targets. This underscores again the impact of technology heterogeneity. ${ }^{14}$

\section{Implications for Designing Emissions Trading}

So far, we have essentially adopted a carbon tax perspective and assumed that a social planner can set $\tau_{j}^{*}$ directly and without constraints. In real-world climate policy, a price on carbon is often established through the "twin" of the tax-based approach: an emissions trading system (ETS). This section explores the implications of our main finding that $\mathrm{CO}_{2}$ prices should not be uniform but should differ across sectors for the design of an ETS.

\footnotetext{
${ }^{13}$ Specifically, we assume that $\left[a_{E}, b_{E}\right]=[-1.52,0.65],\left[a_{I}, b_{I}\right]=[-6.69,-0.041],\left[a_{T}, b_{T}\right]=[-1.70,0.21]$, and $\left[a_{S}, b_{S}\right]=[-2.70,-0.47]$. We note that the "empirically-informed" support for our Monte-Carlo analysis emphasizes the complementarity between $\mathrm{K}-\mathrm{E}$ at the sectoral level. This reflects the difficulty of replacing fossil fuels in all sectors of the economy in the absence of major break-through technologies. In the longrun, $\rho$ may well be very large. Our analysis should thus be viewed as representing a time horizon of several decades at most.

${ }^{14}$ For example, for an emissions reduction target of $40 \%$, optimal sectoral $\mathrm{CO}_{2}$ reduces the policy cost by at least one third in about $25 \%$ of the cases.
} 
POLICY CONTEXT. - Our reasoning is motivated by the policy context for the application of emissions trading systems, which applies to virtually all countries that apply an ETS. Major examples of ETSs are the EU ETS, national trading systems in China and Canada, and regional carbon markets in the U.S. (for an overview of carbon pricing policies, see, for example, World Bank, 2021). In virtually all of these jurisdictions, however, the ETS covers only a subset of sectors and, hence, emissions. Emissions in the remaining parts of the economy are subject to separate environmental regulation. A prominent example of such partitioned regulation is the EU's climate policy, where the overall emissions target is split between sources that fall within and outside the EU ETS. In fact, the European Commission (2021) plans to introduce a second ETS in Europe starting in 2026 that would regulate most of the emissions sources that are currently outside of EU ETS. Hence, two ETSs would exist in parallel.

Against this background, we analyze three important questions that policymakers face in designing cost-effective emissions trading systems: (1) is a single, comprehensive ETS that overcomes partitioned emissions trading desirable, (2) how should the economy-wide $\mathrm{CO}_{2}$ budget be allocated among ETSs, or, equivalently, what should be the emissions cap in each ETS, and (3) how should economic sectors be assigned to ETSs?

A SINGLE COMPREHENSIVE OR MULTIPLE NARROW ETSs?- Motivated by the EU climate policy context, we focus on the case of two ETSs, labeled "ETS-1" and "ETS-2", and examine how the assignment of economic sectors and the allocation of the economy-wide emissions budget to the two ETSs impacts economic costs. In terms of assigning sectors to ETSs, we consider all possible permutations obtained by assigning the four sectors resolved in our quantitative model to two ETSs (see Figure 6). The first case represents in a stylized way the current EU climate policy framework: "EU ETS" contains the "Electricity" and the "Industry" sectors while "Transportation" and "Services" are regulated outside of the EU ETS.

For the emissions trading context, our main finding that optimal $\mathrm{CO}_{2}$ prices differ across sectors leads to the following conclusion:

COROLLARY 1: When social and private discount rates are different and sectoral production technologies are heterogeneous, a single comprehensive ETS is not optimal.

This follows directly from Proposition 3, assuming that prices (carbon taxes) and quantities (emissions trading) are equivalent. ${ }^{15}$ If so, our analysis up to this point can be viewed as an analysis of the regulation of aggregate $\mathrm{CO}_{2}$ emissions by $J$ partitions or ETSs, where the emissions cap of each ETS is given by $\bar{E}_{j}$. Notably, Corollary 1 stands in sharp contrast to the widely-held view among economists that the scope of an ETS should be as broad as possible and that several parallel ETSs should be integrated into a single ETS.

This insight is also supported by our quantitative analysis. Figure 6 shows the reduction in policy cost $\left(\Psi_{h, p}\right)$ from partitioned emissions trading relative to a sin-

\footnotetext{
${ }^{15}$ For example, by abstracting from uncertainties in technology abatement costs (Weitzman, 1974) or market power considerations (Hahn, 1984).
} 


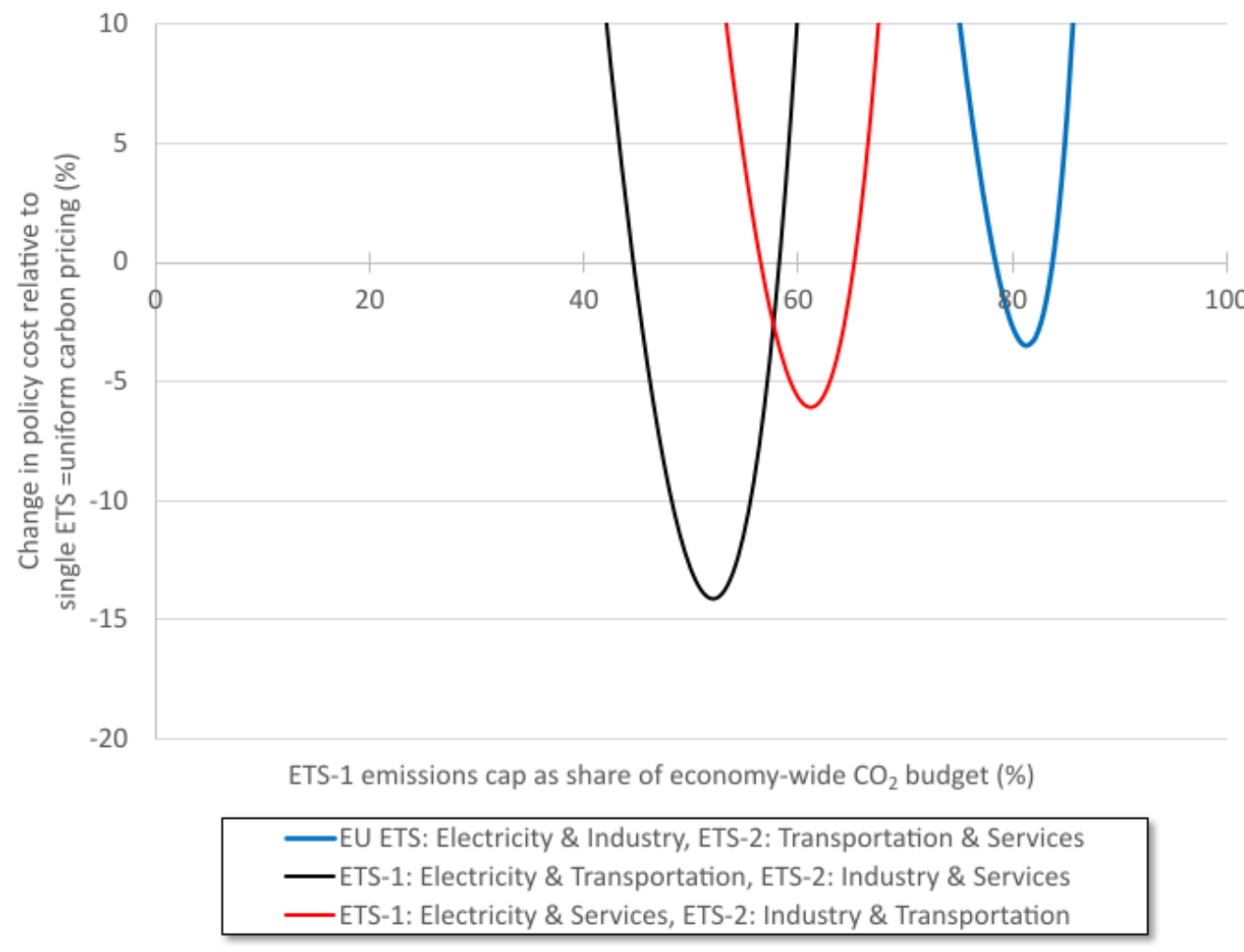

Figure 6. Reduction in policy cost $\left(\Psi_{h, p}\right)$ for $40 \%$ economy-wide emissions reduction under partitioned ETSs relative to uniform carbon pricing for (1) different assignments of sectors to partitions and (2) different allocations of the economy-wide $\mathrm{CO}_{2}$ budget (assuming central-case technology heterogeneity).

gle ETS, or, equivalently, uniform carbon pricing. It displays the three alternative assignments of economic sectors to the two ETSs for different emissions budgets in the "ETS-1". It is straightforward to see that the allocation of the economy-wide emissions budget across the two partitions significantly affects costs. A key main insight borne out by Figure 6 is that partitioned emissions trading can outperform a single ETS that covers all sectors and thus prices carbon uniformly across the economy. The reason is that in an economy with social discounting, it is not optimal to price carbon uniformly. Following the intuition developed by analysis in Sections II and V), differentiating sectoral $\mathrm{CO}_{2}$ prices exploits sectoral differences in substitutability between "dirty" fossil energy and "clean" capital, and help create incentives for investment and capital accumulation beyond is implied by households' savings based on private discounting.

KEY POLICY CHOICES: ASSIGNING SECTORS AND CAPS TO DIFFERENT ETSs.- If a single, comprehensive ETS is not desirable, how should partitioned emissions trading be designed? Unlike in the case of carbon taxes, it is not possible to directly set a sectoral $\mathrm{CO}_{2}$ price. Whether and to what extent partitioned emissions trading outperforms uniform carbon pricing depends on how sectors are assigned to partitions and how the emissions budget is allocated among partitions. First, if too little or 


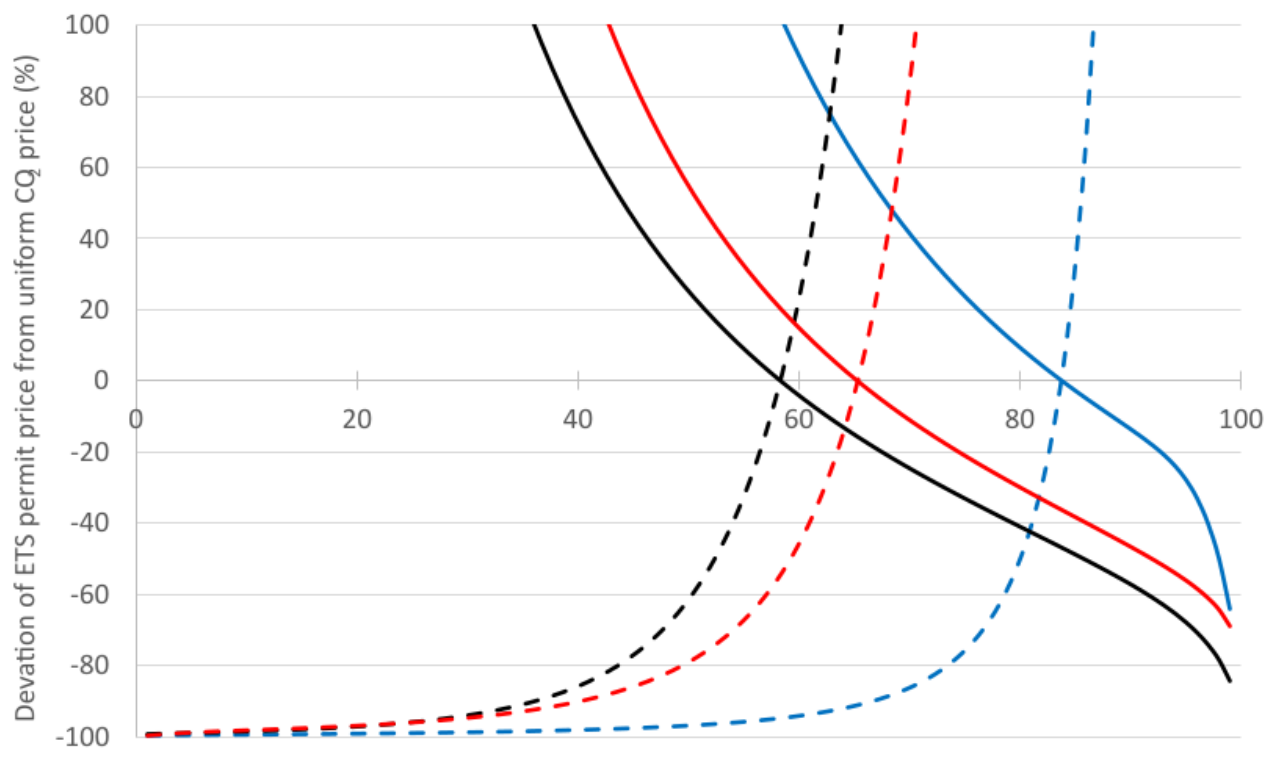

ETS-1 emissions cap as share of economywide $\mathrm{CO}_{2}$ budget (\%)

—ETS-1: Electricity \& Industry

-ETS-1: Electricity \& Transportation

—ETS-1: Electricity \& Services
- - ETS-2: Transportation \& Services

- - ETS-2: Industry \& Services

- - ETS-2: Industry \& Transportation

FiguRE 7. Deviation of ETS permit prices under partitioned trading from uniform carbon pricing for (1) different assignments of sectors to partitions and (2) different allocations of the economy-wide $\mathrm{CO}_{2}$ budget (assuming central-case technology heterogeneity).

too much emissions budget is allocated to one of the two ETSs, costs rise sharply and the efficiency gains from differentiating $\mathrm{CO}_{2}$ across partitions cannot compensate for this. Intuitively, relying largely on an ETS which only covers a subset of emissions source forgoes efficiency gains from exploiting "where-flexibility" across sectors in emissions abatement. Second, the assignment of sectors to partitions plays an important role, too. Based on Proposition 3 and the quantitative results in Section V.B, sectors with a low (high) capital-energy substitutability should receive a relatively high (low) $\mathrm{CO}_{2}$.

The implication of this result is that one should assign sectors to ETSs based on their relative capital-energy substitutability: sectors with a relatively poor substitutability ("Industry" and "Services") should be clustered in one partition and sectors with a relatively high substitutability ("Electricity" and "Transportation") in the other partition. Under such a case, represented by the black line in Figure 6, partitioned emissions trading yields the largest efficiency gains relative to uniform carbon pricing, i.e. a single ETS. The assignment of sectors, on the other hand, as is done in the current EU climate policy, represented by the blue line, leads only to minor efficiency gains.

Since the $\mathrm{CO}_{2}$ permit price cannot differentiate between sectors within a partition, the assignment of sectors to ETSs is important to provide the ability to 
appropriately differentiate $\mathrm{CO}_{2}$ prices in the first place. When the assignment of sectors is chosen such that sectors with low and high capital-energy substitutability are bundled together in one partition, the permit prices between "ETS-1" and "ETS-2" have to differ substantially from one another in order to create reductions in the policy cost relative to uniform carbon pricing (see Figure 7). For example, policy cost are reduced by nearly $15 \%$ if the ETS- 2 permit price deviates downward by about $60 \%$ and the ETS- 1 permit price deviates upward by about $5 \%$ from the uniform $\mathrm{CO}_{2}$ price (black line). With the sectoral assignment reflective of the current situation in EU climate policy (blue line), the permit price between ETSs do not differ much at the point where the reduction in policy cost is maximal. This is because the sectoral assignment does not allow to differentiate the underlying sectoral $\mathrm{CO}_{2}$ prices in an appropriate way: differentiating permit prices across the ETSs would effectively imply high $\mathrm{CO}_{2}$ prices for sectors with a high and low capital-energy substitutability which is not efficient.

\section{Robustness}

FINAL GOOD AGGREGATION.-We have emphasized so far the role technology heterogeneity at the sectoral level. At the level of the final good $\hat{Y}$, we have assumed that sectoral goods $Y_{j}$ are aggregated in a Cobb-Douglas fashion. While this assumption is not uncommon in some of major energy-environment-economy models (Goulder, Hafstead and Williams III, 2016, for example,), sectoral goods may in fact be imperfect substitutes, suggesting an elasticity of substitution (EOS) below 1 (for example, Chen et al., 2015; Capros et al., 2013). Using a CES aggregator with an $\mathrm{EOS}<1$, we find that the optimal sectoral $\mathrm{CO}_{2}$ prices are differentiated to an even higher degree. Everything else equal, we find that the more complementary sectoral goods in final-good aggregation are, the larger (lower) is the optimal $\mathrm{CO}_{2}$ price for sectors for which capital and energy are relatively poor (good) substitutes. The intuition is that when sectoral goods cannot be easily substituted, climate policy has a larger leverage on capital accumulation through differentiating sectoral $\mathrm{CO}_{2}$ prices. To the extent that the central model overestimates substitutability between sectoral goods, the case for optimal $\mathrm{CO}_{2}$ prices that differ across sectors is even stronger.

LIMITED SUBSTITUTABILITY BETWEEN LABOR AND CAPITAL-ENERGY.-The central model assumes a unitary EOS between labor $(L)$ and the capital-energy $(K-E)$ bundle in sectoral production $Y_{j}$. As substitutability between $L$ and $K-E$ decreases in sectors where $K$ and $L$ are relatively highly complementary, the extent of sectoral $\mathrm{CO}_{2}$ price differentiation decreases. In the limiting case, when $L$ and $K-E$ are perfect complements, we find that uniform carbon pricing is approximately optimal. On the other hand, decreasing the substitutability between $L$ and $K-E$ in the sectors where $K$ and $L$ are relatively good substitutes, increases the extent of sectoral $\mathrm{CO}_{2}$ price differentiation diminishes. When $L$ is a complement relative to $K-E$, differentiating $\mathrm{CO}_{2}$ prices does not only affect capital but also distorts to allocation labor across sectors. These costs have to weighed against the benefits from incentivizing the accumulation capital in line with the social discounting motive. 
While there is some evidence in support of the capital-skill complementarity hypothesis at the aggregate production level, the evidence is not very strong (Duffy, Papageorgiou and Perez-Sebastian, 2004). If we assume that the EOS between $L$ and $K-E$ is 0.5 , i.e. taking a midpoint between our central case $(\mathrm{EOS}=1)$ and the case of perfect complements $(\mathrm{EOS}=0)$, we still find that optimal $\mathrm{CO}_{2}$ prices are significantly differentiated between sectors and that welfare gains are $85 \%$ of the gains in the central-case parametrization.

NEAR-ZERO SOCIAL DISCOUNTING.- While we have assumed throughout the analysis that $\zeta_{S}=0$, our main results are robust to using a social discount rate close to zero (Stern, 2006), provided the distance from the private discount rate $(\zeta)$ is sufficiently large. As both discount rates converge, the case for differentiating sectoral $\mathrm{CO}_{2}$ prices diminishes. If $\zeta_{S}=\zeta$, uniform carbon pricing is optimal (see Proposition 2).

PRE-EXISTING, DISTORTIONARY INCOME TAXES.- Our analysis abstracts from preexisting income taxes that are prevalent in today's economies. To the extent that such fiscal instruments are distortionary, optimal carbon taxes have been shown to be smaller compared to using lump-sum taxes to raise government revenues (Bovenberg and Goulder, 1996; Barrage, 2019). If we were to include, for example, positive capital income taxes $\Xi>0$ in our model, we would add another distortion to the capital market in addition to social discounting. To see this, note that from the private Euler equation (4) the steady-state capital rental rate in the decentralized equilibrium is given by $r_{j}=\zeta /(1-\Xi)+\delta_{j}$. The optimal capital rental rate, given the social discount rate and using the Chamley (1986)-Judd (1985) result that capital income should not be taxed, is given by: $r_{j}^{*}=\zeta_{s}+\delta_{j}$. It is thus straightforward to see that a positive capital income tax, like the social discounting externality $\left(\zeta>\zeta_{S}\right)$, means that $r_{j}>r_{j}^{*}$. If capital income taxes cannot be adjusted by policy, the argument for $\mathrm{CO}_{2}$ price differentiation would become even stronger, since the $\tau_{j}^{*}$ would then have to correct for two simultaneous capital market distortions. When capital income taxes could be partially adjusted to reduce the distortion from income taxation, but could not be completely reduced to zero (for example, because an exogenous level of government spending must be financed), the extent of $\mathrm{CO}_{2}$ price differentiation would still be greater than in our central-case model.

\section{Conclusions}

This study revisited the well-known result that a uniform carbon price minimizes the welfare costs of achieving a given economy-wide emissions target. Our analysis revealed the implicit assumptions behind this result. We showed that a uniform carbon price is optimal only when the social and private discount rates are equal. When discount rates differ, strong assumptions are required: it must be possible to subsidize aggregate capital income or the various sectors in an economy must be identical in terms of their substitutability of "dirty" fossil energy with "clean" capital. Otherwise, the result only survives if one assumes that a carbon price has no effect on investments and capital accumulation. These assumptions are not plausible. 
When these assumptions are not met, this paper showed that optimal multisector carbon pricing differentiates $\mathrm{CO}_{2}$ prices across sectors. Technological heterogeneity is key to our finding: sectors in which "dirty" fossil energy (i.e., $\mathrm{CO}_{2}$ emissions) are not easily substitutable with "clean" capital should receive a lower carbon price than sectors where these two inputs are better substitutes. When capital in a given sector is a "poor" substitute for emissions, pricing carbon destroys more capital as compared to reducing the same amount of $\mathrm{CO}_{2}$ emissions in a sector with a higher substitutability. With social discounting, economic agents discount the future too much and differentiating sectoral $\mathrm{CO}_{2}$ prices avoid households failing to invest sufficiently in the economy's capital stocks, boosting capital accumulation and benefiting future generations.

We showed that the differentiation of $\mathrm{CO}_{2}$ prices across sectors has a first-order effect on welfare. For a $40 \%$ economy-wide emissions reduction in the EU economy, we estimated that optimal sectoral prices range from $€ 42.3$ to $€ 116.9$ per ton of $\mathrm{CO}_{2}$, with a mean $\mathrm{CO}_{2}$ price of $€ 74.4 /$ ton. To achieve the same environmental target, a much higher uniform carbon price of $€ 91.3 /$ ton is required. Depending on technological heterogeneity and policy stringency, welfare gains can be as much as half the cost of climate policy under uniform carbon pricing.

We argued that our findings have important implications. First, model-based evaluations of climate policy which (unknowingly) assume that social and private discount rates are equal and ignore technology heterogeneity amount to assuming that a uniform carbon price is optimal. To the extent that these assumptions are not warranted, they overlook better carbon pricing policies and overstate the costs of climate policies. Second, partitioned emissions regulation through separate ETSs within one jurisdiction, as is expected for EU climate policy, does not necessarily lead to higher costs. We showed that two separate ETSs may be superior to a single, comprehensive ETS if sectors are assigned to each ETS such that sectors with relatively low and high capital-energy substitutability are clustered separately. These considerations are relevant to the practical design of ETSs, especially since decarbonization efforts in many countries relies on one or more markets for tradable emission permits as the cornerstone of climate policy.

In this paper, we expounded the assumptions in general equilibrium which underlie the established view that uniform carbon pricing is optimal. Different models offer different policy recommendations and we should settle the mapping from models to policy recommendations, on the one hand, and discuss the applicability of one model versus another, on the other hand. The scope of this paper has been concerned with the former, not the latter.

\section{REFERENCES}

\footnotetext{
Abrell, Jan, and Sebastian Rausch. 2017. "Combining price and quantity controls under partitioned environmental regulation." Journal of Public Economics, 145: 226-242.

Abrell, Jan, Sebastian Rausch, and Giacomo A. Schwarz. 2018. "How robust is the uniform emissions pricing rule to social equity concerns?" Journal of Environmental Economics and Management, 92: $783-814$

Barrage, Lint. 2018. "Be careful what you calibrate for: Social discounting in general equilibrium." Journal of Public Economics, 160: 33-49.
} 
Barrage, Lint. 2019. "Optimal Dynamic Carbon Taxes in a Climate-Economy Model with Distortionary Fiscal Policy." The Review of Economic Studies, 87(1): 1-39.

Belfiori, Maria Elisa. 2017. "Carbon pricing, carbon sequestration and social discounting." European Economic Review, 96: 1-17.

Bernheim, B D. 1989. "Intergenerational altruism, dynastic equilibria, and social welfare." Review of Economic Studies, 56: 119-128.

Böhringer, Christopg, Tim Hoffmann, and Casiano Manrique de Lara-Peñate. 2006. "The efficiency costs of separating carbon markets under the EU emissions trading scheme: A quantitative assessment for Germany." Energy Economics, 28(1): 44-61.

Böhringer, C., J. C. Carbone, and T. F. Rutherford. 2016. "The Strategic Value of Carbon Tariffs." American Economic Journal: Economic Policy, 8: 28-51.

Bovenberg, A. Lans, and Lawrence H. Goulder. 1996. "Optimal Environmental Taxation in the Presence of Other Taxes: General- Equilibrium Analyses." The American Economic Review, 86(4): 9851000 .

Broome, J. 1994. "Discounting the future." Philosophy and Public Affairs, 23: 128-156.

Caplin, Andrew, and John Leahy. 2004. "The Social Discount Rate." Journal of Political Economy, 112: $1257-1268$.

Capros, P, D van Regemorter, L Paroussos, P Karkatsoulis, C Fragkiadakis, S Tsani, I Charalampidis, and T Revesz. 2013. "GEM-E3 Model Documentation." Publications Office of the European Union. European Commission Joint Research Centre Institute for Prospective Technological Studies Technical Reports. https://publications.jrc.ec.europa.eu/repository/handle/JRC83177. Editors: Perry M, Abrell J, Ciscar Martinez J, Pycroft J, Saveyn B.

Chamley, Christophe. 1986. "Optimal Taxation of Capital Income in General Equilibrium with Infinite Lives." Econometrica, 54(3): 607-622.

Chen, Y.H.H., S. Paltsev, J.M. Reilly, J.F. Morris, and M.H. Babiker. 2015. "MIT EPPA6 Model: Economic Growth, Energy Use, and Food Consumption, The."

Costantini, Valeria, Francesco Crespi, and Elena Paglialunga. 2019. "Capital-energy substitutability in manufactoring sectors: methodological and policy implications." Eurasian Business Review, 9: 157182.

Crippa, M., G. Oreggioni, D. Guizzardi, M. Muntean, E. Schaaf, E Lo Vullo, E. Solazzo, F. Monforti-Ferrario, J.G.J Olivier, and E. Vignati. 2019. "Fossil $\mathrm{CO}_{2}$ and GHG emissions of all world countries - 2019 Report." data file "CO2 excl short-cycle org C" retrieved from https://edgar.jrc.ec.europa.eu/overview.php?v=50_GHG on 02.02.2019.

Cropper, M., and W. Oates. 1992. "Environmental Economics: A Survey." Journal of Economic Literature, 30(2): 675-740.

Dasgupta, Partha. 2008. "Discounting climate change." Journal of Risk and Uncertainty, 37: 141-169.

Dissou, Yazid, Lilia Karnizova, and Qian Sun. 2015. "Industry-level Econometric Estimates of Energy-Capital-Labor Substitution with a Nested CES Production Function." Atlantic Economic Journal, 43: 107-121.

Duffy, John, Chris Papageorgiou, and Fidel Perez-Sebastian. 2004. "Capital-skill complementarity? Evidence from a panel of countries." The Review of Economics and Statistics, 86: 327-344.

European Commission. 2020. "Regulation of the European Parliament and of the Council establishing the framework for achieving climate neutrality and amending Regulation (EU) 2018/1999 (European Climate Law)." https://eur-lex.europa.eu/legalcontent/EN/TXT/?qid=1588581905912\&uri=CELEX:52020PC0080.

European Commission. 2021. "Proposal for amending Directive 2003/87/EC, COM(2021) 551 final." July 14, 2021.accessed on July 22, 2021: https://carbonpricingdashboard.worldbank.org/map ata $_{\text {. }}$

Fahri, Emmanuel, and Ivan Werning. 2007. "Inequality and social discounting." Journal of Political Economy, 115: 365-402.

Fawcett, Allen A., Leon C. Clarke, Sebastian Rausch, and John P. Weyant. 2014. "Overview of EMF 24 Policy Scenarios." The Energy Journal, 35: 33-60.

Federal Constitutional Court. 2021. "Constitutional complaints against the Federal Climate Change Act partially successful." Press Release No. 31/2021 of 29 April 2021. https://www.bundesverfassungsgericht.de/SharedDocs/Pressemitteilungen/EN/2021/bvg21-031.html.

Golosov, Mikhail, John Hassler, Per Krusell, and Aleh Tsyvinski. 2014. "Optimal Taxes on fossil fuel in general equilibrium." Econometrica, 82: 41-88.

Goulder, Lawrence, and Ian W. Parry. 2008. "Instrument choice in environmental policy." Review of Environmental Economics and Policy, 2(2): 152-174. 
Goulder, Lawrence H., Marc A. C. Hafstead, and Roberton C. Williams III. 2016. "General Equilibrium Impacts of a Federal Clean Energy Standard." American Economic Journal: Economic Policy, 8: 186-218.

Goulder, L.H., and R. III Williams. 2012. "The choice of discount rate for climate change policy evaluation." Clim. Chang. Econ, 3: 125002.

Hahn, Robert W. 1984. "Market power and transferable property rights." Quarterly Journal of Economics, 99: 753-765.

Hoel, Michael. 1996. "Should a carbon tax be differentiated across sectors?" Journal of Public Economics, 59: $17-32$.

Judd, Kenneth L. 1985. "Redistributive taxation in a simple perfect foresight model." Journal of Public Economics, 28(1): 59-83.

Kaplow, L., E. Moyer, and D.A. Wiesbach. 2010. "The Social Evaluation of Intergenerational Policies and Its Application to Integrated Assessment Models of Climate Change." The B.E. Journal of Economic Analysis and Policy, 10: Article 7.

Koesler, Simon, and Michael Schymura. 2015. "Substitution elasticities in a constant elasticity of substitution framework- empirical estimates using nonlinear least squares." Economic Systems Research, 27: $101-12$

Krutilla, Kerry. 1991. "Environmental Regulation in an Open Economy." Journal of Environmental Economics and Management, 20: 127-142.

Landis, Florian, Sebastian Rausch, and Mirjam Kosch. 2018. "Differentiated Carbon Prices and the Economic Cost of Decarbonization." Environmental Resource Economics, 70: 483-516.

Lu, Yingying, and David I. Stern. 2016. "Substitutability and the Cost of Climate Mitigation Policy." Environmental and Resource Economics, 64: 81-107.

Markusen, James R. 1975. "International externalities and optimal tax structures." Journal of International Economics, 5: 15-295.

Metcalf, Gilbert E. 2009. "Market-based Policy Options to Control U.S. Greenhouse Gas Emissions." Journal of Economic Perspectives, 23: 5-27.

Nordhaus, William. 2015. "Climate Clubs: Overcoming Free-Riding in International Climate Policy." American Economic Review, 105(4): 1339-70.

Nordhaus, William D. 2000. Warming the world: economic models of global warming. London:MIT Press.

Nordhaus, William D. 2007. "A Review of The Stern Review on the Economics of Climate Change." Journal of Economic Literature, XLV: 686-702.

OECD. 2020. Exchange rates (indicator) doi: 10.1787/037ed317-en, Accessed on 12 November 2019.

Okagawa, A., and K. Ban. 2008. "Estimation of Substitution Elasticities for CGE Models." OSIPP Discussion Papers in Economics and Business 08-16.

Paltsev, Sergey, John M. Reilly, Henry D. Jacoby, Richard S. Eckaus, James McFarland, Marcus Sarofim, Malcolm Asadoorian, and Mustafa Babiker. 2005. "The MIT Emissions Prediction and Policy Analysis (EPPA) Model: Version 4."

Papageorgiou, Chris, Marianne Saam, and Patrick Schulte. 2017. "Elasticity of Substitution between Clean and Dirty Energy Inputs: A Macroeconomic Perspective." Review of Economics and Statistics, 99: 281-290.

Pigou, A. 1932. "Wealth and Welfare." MacMillan and Co., 4th edition, London, UK.

Ramsey, F.P. 1928. "A mathematical theory of saving." The Economic Journal, 38: 543-559.

Rauscher, Michael. 1994. "On Ecological Dumping." Oxford Economic Papers, 46: 822-840.

Sandmo, Agnar. 1975. "Optimal Taxation in the Presence of Externalities." Swedish Journal of Economics, 77: 86-98.

Sidgwick, H. 1874. "The Methods of Ethics." Oxford University Press, Oxford, UK.

Solow, Robert. 1974. "The Economics of Resources or the Resources of Economics." The American Economic Review: Papers and Proceedings, 64: 1-14.

Stern, Nicolas. 2006. "The Economics of Climate Change: The Stern Review."

Thompson, T., S. Rausch, R. Saari, and N. Selin. 2014. "A Systems Approach to Evaluating the Air Quality Co-Benefits of US Carbon Policies." Nature Climate Change, 4: 917-923.

Timmer, Marcel, Erik Dietzenbacher, Bart Los, Robert Stehrer, and Gaaitzen J. de Vries. 2015. "An Illustrated User Guide to the World Input- Output Database: the Case of Global Automotive Production." Review of International Economics, 23: 575-605.

Tol, Richard S. J. 2009. "The Economic Effects of Climate Change." Journal of Economic Perspectives, 23(2): 29-51. 
van der Ploeg, Frederick, and Armon Rezai. 2019. "Simple Rules for Climate Policy and Integrated Assessment." Environmental and Resource Economics, 72: 77-108.

van der Werf, E. 2008. "Production Functions for Climate Policy Modeling: An Empirical Analysis." Energy Economics, 30: 2964-2979.

von Below, David. 2012. "Optimal carbon taxes with social and private discounting." Working Paper, SURED Conference, Ascona, Switzerland.

Weitzman, Martin L. 2007. "A Review of The Stern Review on the Economics of Climate Change." Journal of Economic Literature, XLV: 703-724.

Weitzman, M. L. 1974. "Prices vs. quantities." Review of Economic Studies, 41: 477-491.

Weyant, John, Ocen Davidson, Hadi Dowlatabadi, James Edmonds, Michael Grubb, Edward Parson, Richard Richels, Jan Rotmans, Priyadarshi Shukla, Richard Tol, William Cline, and Samuel Fankhauser. 1996. "Integrated Assessment of Climate Change: An Overview and Comparison of Approaches and Results." 367-396.

World Bank. 2020. "Gross savings (\% of GDP)-European Union." accessed on the 25.02.2020, https://data.worldbank.org/indicator/NY.GNS.ICTR.ZS?locations=EU.

World Bank. 2021. "Carbon Pricing Dashboard." accessed on July 22, 2021: https://carbonpricingdashboard.worldbank.org/map ${ }_{d} a t a$. 


\section{Appendix A: Theoretical Derivations and Proofs}

\section{A1. Definition of decentralized equilibrium}

Given the supply of sector emissions $\bar{E}_{j t}, \forall j t$, an equilibrium is given by the sequence of prices and quantities comprising consumption $\left(C_{t}\right)$, capital and labor supply $\left(\bar{K}_{j t}, \bar{L}\right)$, final good and sectoral outputs $\left(\hat{Y}_{t}, Y_{j t}\right)$, demands for capital, labor, and emissions $\left(K_{j t}, L_{j t}, E_{j t}\right)$, investments $I_{t}$, wage and capital rental rates $\left(w_{t}, r_{j t}\right)$, prices for final and sectoral goods $\left(\hat{p}_{t}=1, p_{j t}\right)$, and sectoral prices for $\mathrm{CO}_{2}$ emissions $\left(\tau_{j t}\right)$ such that: (i) $\left(C_{t}\right)$ maximizes lifetime utility of households; (ii) $\left(\hat{Y}_{t}, Y_{j t}\right)$ maximize profits of the final good producer; (iii) $\left(Y_{j t}, K_{j t}, L_{j t}, E_{j t}\right)$ maximize profits of the sectoral goods producers; (iv) the wage and capital rental rates $\left(w_{t}, r_{j t}\right)$ and prices for final and sectoral goods $\left(\hat{p}_{t}=1, p_{j t}\right)$ clear respective goods markets, (v) sectoral carbon prices $\left(\tau_{j t}\right)$ clear sectoral emission markets, and (vi) the evolution of the capital stock is governed by $(9)$.

\section{A2. First-best social planner's problem}

In the first-best setting, the social planner solves the following problem:

$$
\begin{aligned}
& \max _{\left\{K_{j t}, \bar{K}_{j t+1}, Y_{j t}, \hat{Y}_{t}, C_{t}, L_{j t}, \bar{E}_{j t}, E_{j t}, I_{t}\right\}_{j=1}^{J}} \sum_{t=0}^{\infty}\left(\frac{1}{1+\zeta_{S}}\right)^{t}\left[u\left(C_{t}\right)\right. \\
& +\lambda_{t}^{E}\left(\bar{E}_{t}-\sum_{j=1}^{J} E_{j t}\right)+\lambda_{t}^{L}\left(\bar{L}-\sum_{j=1}^{J} L_{j t}\right) \\
& +\sum_{j=1}^{J} \lambda_{j t}^{K_{j}}\left(\bar{K}_{j t}-K_{j t}\right)+\lambda_{t}^{K}\left(-\sum_{j=1}^{J} \bar{K}_{j t+1}+\sum_{j=1}^{J}\left(1-\delta_{j}\right) \bar{K}_{j t}+I_{t}\right) \\
& +\sum_{j=1}^{J} \mu_{j t}\left(Y_{j t}\left(L_{j t}, K_{j t}, E_{j t}\right)-Y_{j t}\right)+\hat{\mu}_{t}\left(\hat{Y}_{t}\left(Y_{1 t}, \ldots, Y_{j t}, \ldots, Y_{J t}\right)-\hat{Y}_{t}\right) \\
& \left.+\mu_{t}\left(\hat{Y}_{t}-C_{t}-I_{t}\right)\right],
\end{aligned}
$$

where $\lambda_{j t}^{E_{j}}, \lambda_{j t}^{K_{j}}, \lambda_{t}^{L}$ denote the shadow prices of input choices in sector $j$ for emissions, capital, and labor, respectively. $\lambda_{t}^{E}$ is the shadow price of economy-wide emissions, $\lambda_{t}^{K}$ the shadow price of aggregate capital, $\mu_{j t}$ and $\hat{\mu}_{j t}$ are the shadow prices of sector $j$ and final output, and $\mu_{t}$ is the shadow cost of consumption. The FOCs are given by:

$$
\begin{aligned}
U_{C t} & =\mu_{t} \\
\mu_{j t} \frac{\partial Y_{j t}\left(L_{j t}, K_{j t}, E_{j t}\right)}{\partial L_{j t}} & =\lambda_{t}^{L} \\
\mu_{j t} \frac{\partial Y_{j t}\left(L_{j t}, K_{j t}, E_{j t}\right)}{\partial E_{j t}} & =\lambda_{t}^{E} \\
\mu_{j t} \frac{\partial Y_{j t}\left(L_{j t}, K_{j t}, E_{j t}\right)}{\partial K_{j t}} & =\lambda_{j t}^{K_{j}} \\
\hat{\mu}_{t} \frac{\partial \hat{Y}_{t}\left(Y_{1 t}, \ldots, Y_{j t}, \ldots, Y_{J t}\right)}{\partial Y_{j t}} & =\mu_{j t} \\
\hat{\mu} t & =\mu_{t} \\
\lambda_{t}^{K} & =\mu_{t} \\
\left(\frac{1}{1+\zeta_{S}}\right)^{t+1} \lambda_{j t+1}^{K_{j}}-\left(\frac{1}{1+\zeta_{S}}\right)^{t} \lambda_{t}^{K}+\left(\frac{1}{1+\zeta_{S}}\right)^{t+1} \lambda_{t+1}^{K}\left(1-\delta_{j}\right) & =0 .
\end{aligned}
$$


Using the conditions for optimal household and firm behavior ((4) and (7)), the decentralized equilibrium coincides with the social optimum:

$$
\begin{aligned}
\mu_{j t} & =p_{j t} U_{C t} \\
\lambda_{t}^{L} & =w_{t} U_{C t} \\
\lambda_{t}^{E} & =\tau_{t} U_{C t} \\
\lambda_{j t}^{K} & =r_{j t} U_{C t} \\
\lambda_{t}^{K} & =\mu_{t}=\hat{\mu}_{t}=U_{C t} .
\end{aligned}
$$

From the conditions above, it is evident that the social optimum can be decentralized by a carbon tax which is uniform across all $j$ sectors-which shows (15):

$$
p_{j t} \frac{\partial Y_{j t}}{\partial E_{j t}}=\tau_{j t}=\lambda_{t}^{E} / U_{C t}, \quad \forall j
$$

and a capital income subsidy (or tax) $\Xi_{t}^{*}$ which is chosen such that the social and private Euler equations coincide for each $t$, respectively:

$$
U_{C t}=\frac{1}{1+\zeta_{S}} U_{C t+1}\left(1+R_{t+1}\right) \quad \text { and } \quad U_{C t}=\frac{1}{1+\zeta} U_{C t+1}\left(1+R_{t+1}\left[1-\Xi_{t+1}\right]\right) .
$$

If $\zeta>\zeta_{S}$, the social optimum entails a subsidy on capital income, i.e. $\Xi_{t+1}<0$, given by the following expression-which shows (16):

$$
\Xi_{t+1}^{*}=\frac{\zeta_{S}-\zeta}{1+\zeta_{S}} \frac{\left(1+R_{t+1}\right)}{R_{t+1}}
$$

\section{A3. Constrained-optimal policy problem}

The constrained planner's problem is identical to the one in A.A2 with the no-subsidy constraint (17) $\left(\Xi_{t} \geq 0 \Longrightarrow U_{C t}(1+\zeta) / U_{C t+1} \leq 1+R_{t+1}\right)$. Using the firms' optimality conditions $\partial \hat{Y}_{t} / \partial K_{j t}=M P K_{j t}=$ $r_{j t}$ and adding the private Euler equation $U_{C t}(1+\zeta) / U_{C t+1}=1+R_{t+1}$ with $R_{t+1}=M P K_{j t+1}-\delta_{j}$, we can write the social planner's problem as:

$$
\begin{aligned}
& \max _{\left\{K_{j t}, \bar{K}_{j t+1}, Y_{j t}, C_{t}, \hat{Y}_{t}, L_{j t}, E_{j t}, I_{t}\right\}_{j=1}^{J}} \sum_{t=0}^{\infty}\left(\frac{1}{1+\zeta_{S}}\right)^{t}\left[u\left(C_{t}\right)\right. \\
& +\lambda_{t}^{E}\left(\bar{E}_{t}-\sum_{j=1}^{J} E_{j t}\right)+\lambda_{t}^{L}\left(\bar{L}-\sum_{j=1}^{J} L_{j t}\right)+\sum_{j=1}^{J} \lambda_{j t}^{K_{j}}\left(\bar{K}_{j t}-K_{j t}\right) \\
& +\lambda_{t}^{K}\left(-\sum_{j=1}^{J} \bar{K}_{j t+1}+\sum_{j=1}^{J}\left(1-\delta_{j}\right) \bar{K}_{j t}+I_{t}\right) \\
& +\sum_{j=1}^{J} \mu_{j t}\left(Y_{j t}\left(L_{j t}, K_{j t}, E_{j t}\right)-Y_{j t}\right)+\hat{\mu}_{t}\left(\hat{Y}_{t}\left(Y_{1 t}, \ldots, Y_{j t}, \ldots, Y_{J t}\right)-\hat{Y}_{t}\right) \\
& \left.+\mu_{t}\left(\hat{Y}_{t}-C_{t}-I_{t}\right)+\hat{\phi}_{t+1}\left(-\frac{U_{C t}(1+\zeta)}{U_{C t+1}}+\left(1+R_{t+1}\right)\right)+\sum_{k=1}^{J} \phi_{k t+1}^{K}\left(-R_{t+1}+M P K_{k t+1}-\delta_{k}\right)\right] .
\end{aligned}
$$

$\hat{\phi}_{t+1}$ denotes the shadow costs of the no-subsidy constraint and $\phi_{k t+1}^{K}$ are the shadow costs of the constrained capital prices. Both constraints are present from period $t>0$ onwards. $M P K_{k t}$ is the marginal 
product of capital in sector $k$ at time $t$ and defined as: $M P K_{k t}=\gamma_{k}\left(1-\alpha_{k}\right) \theta_{k t}^{K} \hat{Y}_{t} K_{k t}^{-1}$, where $\gamma_{k}$ is the value share of the sectoral output relative to aggregated output, $1-\alpha_{k}$ is the value share of the emissions-capital bundle in sectoral output and $\theta_{k t}^{K}$ is the value share of capital in the emissions-capital bundle.

The FOCs for $t>0$ read:

$$
\begin{gathered}
C_{t}: \quad U_{c t}-\mu_{t}-\hat{\phi}_{t+1} \frac{U_{c c t}(1+\zeta)}{U_{c t+1}}+\left(1+\zeta_{S}\right) \hat{\phi}_{t} \frac{U_{c t-1}(1+\zeta)}{U_{c t}} \frac{U_{c c t}}{U_{c t}}=0 \\
\hat{Y}_{t}: \quad \mu_{t}-\hat{\mu}_{t}+\left(1+\zeta_{S}\right) \sum_{k=1}^{J} \phi_{k t}^{K} M P K_{k t} \hat{Y}_{t}^{-1}=0 \\
I_{t}: \quad \lambda_{t}^{K}-\mu_{t}=0 \\
\bar{K}_{j t+1}:-\lambda_{t}^{K}+\frac{1}{1+\zeta_{S}} \lambda_{t+1}^{K}\left(1-\delta_{j}\right)+\frac{1}{1+\zeta_{S}} \lambda_{j t+1}^{K_{j}}=0 \\
Y_{j t}: \quad \hat{\mu}_{t} \frac{\partial \hat{Y}_{t}}{\partial Y_{j t}}-\mu_{j t}=0 \\
K_{j t}: \quad \mu_{j t} \frac{\partial Y_{j t}}{\partial K_{j t}}-\lambda_{j t}^{K_{j}}+\left(1+\zeta_{S}\right) \phi_{j t}^{K} \frac{\partial M P K_{j t}}{\partial K_{j t}}=0 \\
L_{j t}: \quad \mu_{j t} \frac{\partial Y_{j t}}{\partial L_{j t}}-\lambda_{t}^{L}=0 \\
E_{j t}: \quad \mu_{j t} \frac{\partial Y_{j t}}{\partial E_{j t}}-\lambda_{t}^{E}+\left(1+\zeta_{S}\right) \phi_{j t}^{K} \frac{\partial M P K_{j t}}{\partial E_{j t}}=0 .
\end{gathered}
$$

The Lagrangian multiplier $\lambda_{j t+1}^{K_{j}}$ is thus given by:

$$
\lambda_{j t+1}^{K_{j}}=\lambda_{t}^{K}\left(1+\zeta_{S}\right)-\lambda_{t+1}^{K}\left(1-\delta_{j}\right),
$$

with:

$$
\lambda_{j t}^{K}=\mu_{t}=\hat{\mu}_{t}-\left(1+\zeta_{S}\right) \sum_{k=1}^{J} \phi_{k t}^{K} M P K_{k t} \hat{Y}_{t}^{-1}
$$

Using the conditions for optimal household and firm behavior (4) and (7), respectively, the decentralized equilibrium coincides with the social optimum if:

$$
\begin{aligned}
\mu_{j t} & =p_{j t} U_{C t} \\
\lambda_{t}^{L} & =w_{t} U_{C t} \\
\lambda_{j t}^{K_{j}}-\left(1+\zeta_{S}\right) \phi_{j t}^{K} \frac{\partial M P K_{j t}}{\partial K_{j t}} & =r_{j t} U_{C t} \\
\lambda_{t}^{E}-\left(1+\zeta_{S}\right) \phi_{j t}^{K} \frac{\partial M P K_{j t}}{\partial E_{j t}} & =\tau_{j t} U_{C t} \\
\hat{\mu}_{t} & =U_{c t} .
\end{aligned}
$$

The constrained-optimal pricing rule for carbon emissions in sector $j$ in the decentralized economy is thus given by:

$$
\underbrace{\mu_{j t}}_{=U_{c t} p_{j t}} \frac{\partial Y_{j t}}{\partial E_{j t}}=\underbrace{\lambda_{t}^{E}}_{=U_{c t} \tau_{t}}-\left(1+\zeta_{S}\right) \phi_{j t}^{K} \frac{\partial M P K_{j t}}{\partial E_{j t}},
$$


which shows (18) in Proposition 1.

\section{A4. Constrained-optimal carbon pricing in the steady-state equilibrium}

The steady-state equilibrium conditions are given by:

$$
\begin{aligned}
\lambda^{K} & =U_{c}-\left(1+\zeta_{S}\right) \sum_{k=1}^{J} \phi_{k}^{K} M P K_{k} \hat{Y}^{-1} \\
\lambda_{j}^{K_{j}} & =\lambda^{K}\left(\zeta_{S}+\delta_{j}\right) \\
U_{c} r_{j} & =\lambda_{j}^{K_{j}}-\left(1+\zeta_{S}\right) \phi_{j}^{K} \frac{\partial M P K_{j}}{\partial K_{j}} \\
r_{j} & =\zeta+\delta_{j}
\end{aligned}
$$

where $M P K_{k}$ denotes the marginal product of capital in sector $k$. Using all FOCs with respect to $K_{j}$ yields an expression for $\phi_{j}^{K}$ :

$$
\phi_{j}^{K}=-U_{c}\left(\frac{\zeta-\zeta_{S}}{1+\zeta_{S}}\right) \frac{1+\sum_{k=1}^{J}\left(\delta_{k}-\delta_{j}\right)\left(\frac{\partial M P K_{k}}{\partial K_{k}}\right)^{-1} M P K_{k} \hat{Y}^{-1}}{1+\sum_{k=1}^{J}\left(\zeta_{S}+\delta_{k}\right)\left(\frac{\partial M P K_{k}}{\partial K_{k}}\right)^{-1} M P K_{k} \hat{Y}^{-1}}\left(\frac{\partial M P K_{j}}{\partial K_{j}}\right)^{-1} .
$$

Using the steady-state analogue of (18) for efficient carbon prices under the constrained policy:

$$
\underbrace{U_{c} \tau_{j}}_{=U_{c t} p_{j t} \partial Y_{j t} / \partial E_{j t}}=\underbrace{U_{c} \tau}_{=\lambda^{E}}-\left(1+\zeta_{S}\right) \phi_{j}^{K}\left(\frac{\partial M P K_{j}}{\partial E_{j}}\right),
$$

we can write for all $j$ :

$$
\tau_{j}=\tau+\left(\zeta-\zeta_{S}\right)\left[\frac{1+\sum_{k=1}^{J}\left(\delta_{k}-\delta_{j}\right)\left(\frac{\partial M P K_{k}}{\partial K_{k}}\right)^{-1} M P K_{k} \hat{Y}^{-1}}{1+\sum_{k=1}^{J}\left(\zeta_{S}+\delta_{k}\right)\left(\frac{\partial M P K_{k}}{\partial K_{k}}\right)^{-1} M P K_{k} \hat{Y}^{-1}}\right] \frac{\left(\frac{\partial M P K_{j}}{\partial E_{j}}\right)}{\left(\frac{\partial M P K_{j}}{\partial K_{j}}\right)} .
$$

The $M P K$ and the marginal product of emission $(M P E)$ are given, respectively, by:

$$
M P K_{j}=\gamma_{j}\left(1-\alpha_{j}\right) \theta_{j}^{K} \hat{Y} K_{j}^{-1} \stackrel{!}{=} r_{j}, \quad M P E_{j} \quad=\gamma_{j}\left(1-\alpha_{j}\right) \theta_{j}^{E} \hat{Y} E_{j}^{-1} \stackrel{!}{=} \tau_{j}
$$

where $\theta_{j}^{K}$ is the value share of capital within the capital-emissions bundle and $\theta_{j}^{E}=1-\theta_{j}^{K}$ the value share of emissions. $\theta_{j}^{K}$ can be expressed in terms of technology parameters and equilibrium prices:

$$
\theta_{j}^{K}=\frac{\beta_{K j} H_{K j}^{\rho_{j}} K_{j}^{\rho_{j}}}{\beta_{K j} H_{K j}^{\rho_{j}} K_{j}^{\rho_{j}}+\beta_{E j} H_{E j}^{\rho_{j}} E_{j}^{\rho_{j}}}=\frac{\beta_{K j} H_{K j}^{\rho_{j}}\left(\frac{r_{j}}{\beta_{K j} H_{K j}^{\rho_{j}}}\right)^{\frac{\rho_{j}}{\rho_{j}-1}}}{\beta_{K j} H_{K j}^{\rho_{j}}\left(\frac{r_{j}}{\beta_{K j} H_{K j}^{\rho_{j}}}\right)^{\frac{\rho_{j}}{\rho_{j}-1}}+\beta_{E j} H_{E j}^{\rho_{j}}\left(\frac{\tau_{j}}{\beta_{E j} H_{E j}^{\rho_{j}}}\right)^{\frac{\rho_{j}}{\rho_{j}-1}}} .
$$

From this it follows that:

$$
\frac{\partial M P K_{j}}{\partial K_{j}}=\left[\left(1-\theta_{j}^{K}\right) \rho_{j}-1\right] K_{j}^{-1} M P K_{j}
$$




$$
\frac{\partial M P K_{j}}{\partial E_{j}}=-\rho_{j} \theta_{j}^{K} K_{j}^{-1} M P E_{j}
$$

and we can re-write (A4) to obtain the constrained-optimal sectoral emissions pricing rule (19) as:

$$
\tau_{j}=\tau+\left(\zeta-\zeta_{S}\right)\left(\frac{1+\sum_{k=1}^{J}\left(\delta_{k}-\delta_{j}\right) \Psi_{k}}{1+\sum_{k=1}^{J}\left(\zeta_{S}+\delta_{k}\right) \Psi_{k}}\right)\left(\frac{-\rho_{j} \theta_{j}^{K} \tau_{j}}{\left(\left(1-\theta_{j}^{K}\right) \rho_{j}-1\right) r_{j}}\right), \quad \forall j
$$

where $\Psi_{k}=\left[\left(1-\theta_{k}^{K}\right) \rho_{k}-1\right]^{-1} K_{k} Y^{-1}$ and $K_{k} Y^{-1}=\frac{\gamma_{k} \alpha_{k} \theta_{k}^{K}}{\zeta+\delta_{k}}$.

To prove Proposition 3, we proceed in two parts. Note first that $\bar{\phi}_{j} \neq \bar{\phi}_{k}$ if either $\delta_{j} \neq \delta_{k}, \beta_{K j} \neq \beta_{K k}$, $H_{K j} \neq H_{K k}, H_{E j} \neq H_{E k}$, or $\rho_{j} \neq \rho_{k}$. It is then straightforward to see that technology heterogeneity implies that $\Gamma_{j} \neq \Gamma_{k}$, as the denominators take on different values depending on the sector-specific technology parameters, and $\tau_{j} \neq \tau_{k}$. The second part of the proposition follows readily from inspecting the expressions for $\bar{\phi}_{j}$ and $\rho_{j}$ and $\theta_{j}^{K}$ in (19). First, $\tau_{j}$ increases with $\rho_{j}$ because $\partial\left(\rho_{j} \theta_{j}^{K}\right) / \partial \rho_{j}>0$ and thus $\tau_{j}>\tau_{k}$ whenever $\rho_{j}>\rho_{k}$, ceteris paribus. Second, $\beta_{K j}, H_{K j}, H_{E j}$ and $\delta_{j}$ impact on sectoral carbon prices depends on the elasticity parameter $\rho_{j}$. Whenever $\rho_{j}=\rho_{k}>0$, a higher capital value share $\left(\theta_{j}^{K}>\theta_{k}^{K}\right)$ leads to higher carbon prices $\left(\tau_{j}>\tau_{k}\right)$. We thus investigate how $\theta_{j}^{K}$ changes with the respective parameters:

- $\left.\frac{\partial \theta_{j}^{K}}{\partial \beta_{K j}}\right|_{\rho_{j}>0}>0$ and $\tau_{j}$ increases with $\beta_{K j}$ when $\rho_{j}>0$.

- $\left.\frac{\partial \theta_{j}^{K}}{\partial H_{K j}}\right|_{\rho_{j}>0}>0$ and $\tau_{j}$ increases with $H_{K j}$ when $\rho_{j}>0$.

- $\left.\frac{\partial \theta_{j}^{K}}{\partial H_{E j}}\right|_{\rho_{j}>0}<0$ and $\tau_{j}$ decreases with $H_{E j}$ when $\rho_{j}>0$.

- $\left.\frac{\partial \theta_{j}^{K}}{\partial \delta_{j}}\right|_{\rho_{j}>0}<0$ and $\tau_{j}$ decreases with $\delta_{j}$ when $\rho_{j}>0$.

Whenever $\rho_{j}=\rho_{k}<0$, a higher capital value share $\left(\theta_{j}^{K}>\theta_{k}^{K}\right)$ leads to lower carbon prices $\left(\tau_{j}<\tau_{k}\right)$. We thus investigate how $\theta_{j}^{K}$ changes with the respective parameters:

- $\left.\frac{\partial \theta_{j}^{K}}{\partial \beta_{K j}}\right|_{\rho_{j}<0}<0$ and $\tau_{j}$ decreases with $\beta_{K j}$ when $\rho_{j}<0$.

- $\left.\frac{\partial \theta_{j}^{K}}{\partial H_{K j}}\right|_{\rho_{j}<0}<0$ and $\tau_{j}$ decreases with $H_{K j}$ when $\rho_{j}<0$.

- $\left.\frac{\partial \theta_{j}^{K}}{\partial H_{E j}}\right|_{\rho_{j}<0}>0$ and $\tau_{j}$ increases with $H_{E j}$ when $\rho_{j}<0$.

- $\left.\frac{\partial \theta_{j}^{K}}{\partial \delta_{j}}\right|_{\rho_{j}<0}>0$ and $\tau_{j}$ increases with $\delta_{j}$ when $\rho_{j}<0$.

Proposition 3 summarizes these findings.

\section{A5. Steady-state conditions}

The household's Euler equation with $\Xi=0$ and capital investments in steady-state reveal

$$
r_{j}=\zeta+\delta_{j}, \quad I=\sum_{j=1}^{J} \delta_{j} K_{j}
$$


The final good sector's FOCs for all $j$ are

$$
\gamma_{j} \frac{\prod_{k=1}^{J} Y_{k}^{\gamma_{k}}}{Y_{j}}=p_{j}
$$

The optimality conditions for sectoral output are

$$
w=\alpha_{j} p_{j} \frac{Y_{j}}{L_{j}}, \quad r_{j}=p_{j} \frac{\partial Y_{j}}{\partial K_{j}}, \quad \tau_{j}=p_{j} \frac{\partial Y_{j}}{\partial E_{j}},
$$

where

$$
\begin{aligned}
\frac{\partial Y_{j}}{\partial K_{j}} & =\left(1-\alpha_{j}\right) \beta_{K j}\left(H_{K j} K_{j}\right)^{\rho_{j}} / K_{j} \times L_{j}^{\alpha_{j}}\left[\beta_{K j}\left(H_{K j} K_{j}\right)^{\rho_{j}}+\beta_{E j}\left(H_{E j} E_{j}\right)^{\rho_{j}}\right]^{\frac{1-\alpha_{j}}{\rho_{j}}-1} \\
\frac{\partial Y_{j}}{\partial E_{j}} & =\left(1-\alpha_{j}\right) \beta_{E j}\left(H_{E j} E_{j}\right)^{\rho_{j}} / E_{j} \times L_{j}^{\alpha_{j}}\left[\beta_{K j}\left(H_{K j} K_{j}\right)^{\rho_{j}}+\beta_{E j}\left(H_{E j} E_{j}\right)^{\rho_{j}}\right]^{\frac{1-\alpha_{j}}{\rho_{j}}-1} .
\end{aligned}
$$

Labor supply is given by $\sum_{j} L_{j}=\bar{L}$ and total emission is given by $\sum_{j} E_{j}=\bar{E}$. Final output and sectoral output are given by

$$
\hat{Y}=\prod_{j=1}^{J} Y_{j}^{\gamma_{j}}, \quad Y_{j}=L_{j}^{\alpha_{j}}\left[\beta_{K j}\left(H_{K j} K_{j}\right)^{\rho_{j}}+\beta_{E j}\left(H_{E j} E_{j}\right)^{\rho_{j}}\right]^{\frac{1-\alpha_{j}}{\rho_{j}}} .
$$

Consumption is thus $C=\hat{Y}-I$. 


\section{Appendix B: Mappings of Sectors and Emissions Data to Model Sectors}

We map the sectors in the WIOD dataset, as identified by alphabetic categories according to the International Standard Industrial Classification of All Economic Activities (ISIC), Revision 4, to the four sectoral aggregates in our model. The many-to-one sectoral mapping is as follows: sectors B, D, E are aggregated in "Electricity", sectors C, F in "Industry", sectors H in "Transportation", and sectors G, $\mathrm{I}-\mathrm{U}$ in "Services".

We use information on $\mathrm{CO}_{2}$ emissions at the sectoral level from the European Commission's EDGAR database (Emission Database for Global Atmospheric Research, Crippa et al., 2019) and link emissions from fossil-fuel combustion as well as process emissions to the sectors using the mapping shown in Table B1.

TABLE B1. Mapping of emissions data categories to model sectors.

\begin{tabular}{|c|c|}
\hline Category in the data & Model sector \\
\hline Biological Treatment of Solid Waste & Electricity \\
\hline Emissions from biomass burning & Electricity \\
\hline Incineration and Open Burning of Waste & Electricity \\
\hline Main Activity Electricity and Heat Production & Electricity \\
\hline Oil and Natural Gas & Electricity \\
\hline Petroleum Refining - Manufacture of Solid Fuels and Other Energy Industries & Electricity \\
\hline Solid Fuels & Electricity \\
\hline Solid Waste Disposal & Electricity \\
\hline Wastewater Treatment and Discharge & Electricity \\
\hline Chemical Industry & Industry \\
\hline Manufacturing Industries and Construction & Industry \\
\hline Metal Industry & Industry \\
\hline Cement Production & Industry \\
\hline Lime Production & Industry \\
\hline Glass Production & Industry \\
\hline Other Process Uses of Carbonates & Industry \\
\hline Non-Energy Products from Fuels and Solvent Use & Industry \\
\hline Liming & Industry \\
\hline Urea application & Industry \\
\hline Civil Aviation & Transportation \\
\hline Other Transportation & Transportation \\
\hline Railways & Transportation \\
\hline Road Transportation & Transportation \\
\hline Water-borne Navigation & Transportation \\
\hline Non-Specified & Services \\
\hline Other Sectors & Services \\
\hline
\end{tabular}


Download ZEW Discussion Papers from our ftp server:

http://ftp.zew.de/pub/zew-docs/dp/

or see:

https://www.ssrn.com/link/ZEW-Ctr-Euro-Econ-Research.html

https://ideas.repec.org/s/zbw/zewdip.html

$$
\text { // }
$$

IMPRINT

ZEW - Leibniz-Zentrum für Europäische Wirtschaftsforschung GmbH Mannheim

ZEW - Leibniz Centre for European

Economic Research

L 7,1 68161 Mannheim · Germany

Phone +49621 1235-01

info@zew.de·zew.de

Discussion Papers are intended to make results of ZEW research promptly available to other economists in order to encourage discussion and suggestions for revisions. The authors are solely responsible for the contents which do not necessarily represent the opinion of the ZEW. 